\title{
Shell isolated nanoparticle enhanced Raman spectroscopy for mechanistic investigation of electrochemical reactions
}

\author{
Andi Haryanto and Chan Woo Lee* (D)
}

\begin{abstract}
Electrochemical conversion of abundant resources, such as carbon dioxide, water, nitrogen, and nitrate, is a remarkable strategy for replacing fossil fuel-based processes and achieving a sustainable energy future. Designing an efficient and selective electrocatalysis system for electrochemical conversion reactions remains a challenge due to a lack of understanding of the reaction mechanism. Shell-isolated nanoparticle-enhanced Raman spectroscopy (SHINERS) is a promising strategy for experimentally unraveling a reaction pathway and rate-limiting step by detecting intermediate species and catalytically active sites that occur during the reaction regardless of substrate. In this review, we introduce the SHINERS principle and its historical developments. Furthermore, we discuss recent SHINERS applications and developments for investigating intermediate species involved in a variety of electrocatalytic reactions.
\end{abstract}

Keywords: Electrocatalysis, In situ spectroscopy, Raman scattering, Reaction mechanisms, Shell-isolated nanoparticle-enhanced Raman spectroscopy

\section{Introduction}

Environmental deterioration has become a major concern around the world. Energy-generating processes are currently reliant on fossil fuels, which emit greenhouse gases, such as carbon dioxide $\left(\mathrm{CO}_{2}\right)$, methane, and nitrous oxide [1-3]. Based on the British Petroleum Statistical Review of World Energy in 2020, fossil fuels accounted for $84.3 \%$ of the overall energy consumption in 2019. In line with this, $\mathrm{CO}_{2}$ emissions increased by $0.5 \%$ in 2018, reaching 34,169 million tons [4]. Accumulated $\mathrm{CO}_{2}$ molecules in the atmosphere primarily contribute to environmental deterioration by lowering seawater $\mathrm{pH}$ and causing global warming through the greenhouse effect [5].

Replacing fossil fuels with renewable energy sources, such as hydropower, wind, and solar, as well as directly converting $\mathrm{CO}_{2}$ into other chemicals using renewable energy sources, have all proven to be effective strategies

${ }^{*}$ Correspondence: cwlee1@kookmin.ac.kr

Department of Chemistry, Kookmin University, Seoul 0207, South Korea for mitigating $\mathrm{CO}_{2}$ emissions. Hydrogen is another promising candidate for replacing fossil fuels because of its ability to transport energy [6]. Chemical energy is converted to electricity in a fuel cell via hydrogen oxidation reaction and oxygen reduction reaction (ORR). Moreover, renewable energy sources can be used to obtain green hydrogen via a water-splitting reaction [7]. These approaches have been studied and tested as a possible solution to environmental problems.

It is important to investigate the reaction pathway and rate-determining step (RDS) in environmentally friendly energy conversion processes, where essential intermediate species are involved in the reaction. Researchers could develop new ideas based on the RDS to produce a superior electrocatalyst with optimal binding strengths for the key intermediates [8]. For example, $\mathrm{OOH}^{*}$ and $\mathrm{CO}^{*}$ intermediates are involved in the electrochemical reduction of $\mathrm{CO}_{2}$ to $\mathrm{CO}$. When the $\mathrm{COOH}^{*}$ binding strength is extremely weak to be adsorbed at a specific surface, increasing the binding strength can improve catalytic performance by facilitating the RDS $[9,10]$. 
In situ surface-enhanced Raman scattering (SERS) has been used to investigate the reaction mechanisms of various electrochemical reactions, including hydrogen evolution reaction (HER) [11], oxygen evolution reaction (OER) [12], ORR [13], and $\mathrm{CO}_{2}$ reduction reaction $\left(\mathrm{CO}_{2} \mathrm{RR}\right)$ [14]. Raman measurement collects the inelastic photon scattered from the excitation of vibrational modes within the sample and at the surface. It can detect catalyst phase evolution and intermediate species adsorbed on the catalyst surface. In situ SERS allows for detection of more surface vibrations in a broader spectral range, such as metal-oxygen and metal-carbon in the low wavenumber region, in comparison with in situ attenuated total reflection surface-enhanced Infrared absorption spectroscopy (ATR-SEIRAS) [15, 16]. In addition, the prisms used as a substrate in ATR-SEIRAS impose limitations in terms of electrolyte $\mathrm{pH}$ and available wavenumber range [17], while SERS is measured on an actual catalyst electrode. Furthermore, analysis of SERS spectra is straight-forward because background subtraction is not needed as in ATR-SEIRAS [18]. However, the catalyst surfaces that can be investigated by SERS are mostly $\mathrm{Au}, \mathrm{Ag}$, and $\mathrm{Cu}$ metals that have an intrinsic ability to facilitate surface plasmon resonance and amplify Raman signals generated at the surface. Other metals, such as $\mathrm{Pd}, \mathrm{Pt}, \mathrm{Ni}$, and $\mathrm{Co}$, have also been investigated, but the Raman enhancement was relatively low, and the adsorption of the chemical species on catalyst surfaces was difficult to detect [19].

To overcome the limitation, shell-isolated nanoparticle-enhanced Raman spectroscopy (SHINERS) has been proposed as a general method for enhancing Raman signals from surface intermediate species in electrocatalysis reactions. The plasmonic core in SHINERS is coated with a thin protective layer, which prevents direct interaction between a probe molecule and the plasmonic core while allowing for surface plasmon resonance. The shell-isolated nanoparticle (SHIN) is then placed on the target substrate to detect molecules adsorbed at the surface of a substrate. In this regard, it has been reported that this method can be applied to any kind of substrate [20]. In addition, the shell can improve the plasmonic core stability in a wide range of $\mathrm{pH}$ and electrolytes [21]. Here, the historical development and fundamental principle of SHINERS technology are discussed. Next, recent advances of SHINERS in investigating reaction mechanisms of electrochemical reactions, such as ORR, CORR, $\mathrm{CO}$ electrooxidation reaction, OER, and nitrate reduction reaction $\left(\mathrm{NO}_{3} \mathrm{RR}\right)$, are outlined. Finally, the potential application of SHINERS in other electrocatalysis fields is discussed.

\section{Principle of SHINERS}

The enhancement in SERS mainly originates from the localized surface plasmon resonance (LSPR). The LSPR is a special phenomenon that occurs by collective coherent oscillating modes of electrons on nanoparticle surfaces under light illumination, as illustrated in Fig. 1a. The oscillating mode causes localized electromagnetic fields around the nanoparticle surface, which contribute to the enhancement of Raman intensity [22-24].

The gap distance between each nanoparticle also affects the SERS enhancement factor. The local electromagnetic field in the nanogap between two or more nanoparticles is strong because of the electromagnetic coupling of the nanoparticles. According to Tian's group, the SERS enhancement factor of $\mathrm{Au}$ nanosphere dimer increased by 10,000 times from $10^{5}$ to $10^{9}$ when the gap distance reduced from 10 to $2 \mathrm{~nm}$ [22]. However, reducing the nanogap between each nanoparticle has its limitation since electron quantum tunneling effects between the coupled nanoparticles will occur. The electron tunneling, e.g., charge transfer across the narrow junction in the sub-nanometer level, decreases the electric field across
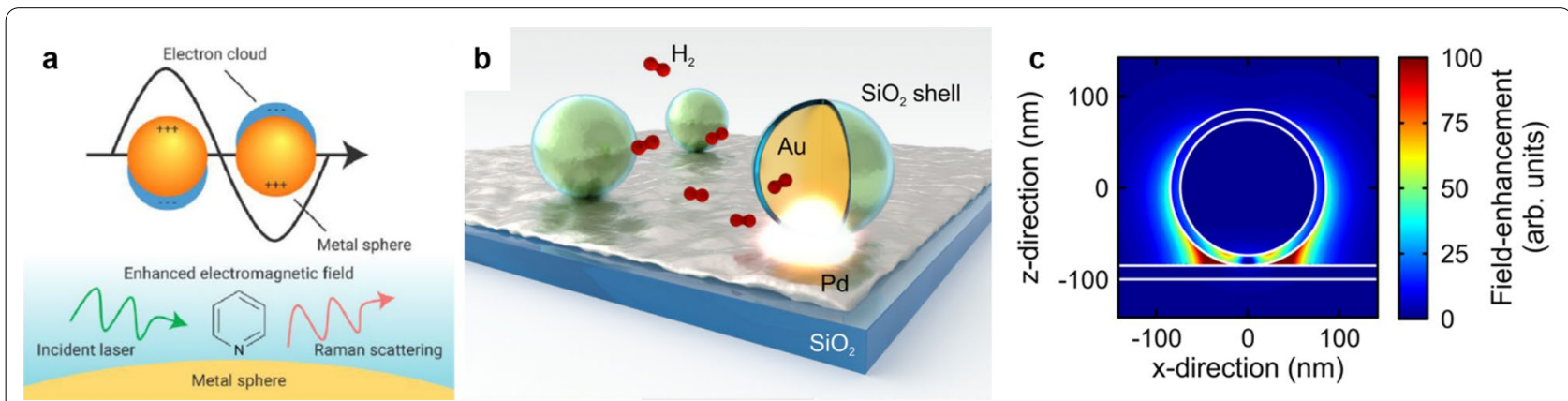

Fig. 1 a Illustration of the localized surface plasmon resonance on the nanoparticle surface, reproduced with permission from [24]. Copyright (2020) Elsevier B.V. b SERS measurement at the interface of the core-shell nanoparticle and the electrode. c The distribution of field-enhancement around the surface of a core-shell nanoparticle, reproduced with permission from [23]. Copyright (2013) American Chemical Society 
the junction and thus causes a considerable reduction in the electromagnetic field enhancements across the dimer junction [25].

At the interface of the core-shell nanoparticle and the plasmonically inactive electrode (Fig. 1b and c), the field enhancement is more intensified around the contact between the core-shell nanoparticle and the electrode film. Under light illumination, the core-shell nanoparticle induces a mirror plasmon oscillation from the electrode [26]. The coupling of those oscillating plasmon results in a high electromagnetic field concentrated around the contact point, which further contribute to the amplification of Raman intensity from probed molecules.

Figure 2 shows the historical progress on SERS application in catalysis, from the discovery of the SERS effect to the borrowing strategy, SHINERS method, and SHINERS satellite structures. In 1974, Fleischmann et al. discovered that the Raman signal of adsorbed pyridine was significantly enhanced on electrochemically roughened silver electrodes [28]. Later on, in 1977, Van Duyne et al. reported that the Raman signal from pyridine adsorbed was about $10^{5}-10^{6}$ times stronger than that of bulk pyridine [29]. The researchers initially concluded that the significant enhancement of the Raman signal was due to an increase in the amount of pyridine absorbed at the electrode surface. However, it was later revealed that the enhancement was due to the localized electromagnetic field formed around the metallic nanostructures [19].

After the SERS effect findings, many researchers have explored different types of catalysts for Raman signal enhancement [19]. However, only $\mathrm{Ag}, \mathrm{Au}$, and $\mathrm{Cu}$ metals have been found to have high enhancement factors of Raman signals because these metals intrinsically generate a large electromagnetic field around the metal nanoparticle surface $[21,30]$. To overcome the limitation and probe various catalyst surfaces in addition to $\mathrm{Ag}, \mathrm{Au}$, and $\mathrm{Cu}$, a borrowing strategy has been utilized [27]. As shown in Fig. 2, the objective was to deposit a thin layer of the catalytically active material of interest, represented by silver color, on the yellow-colored SERS-active material. As a result, the catalyst surface can borrow a localized electric field from the under layer. Despite the utility of the borrowing strategy, obtaining vibrational information of adsorbed molecules on atomically flat surfaces, such as various single-crystalline electrodes, which are widely used as a model system in surface science and electrochemistry, was difficult because flat electrodes are relatively inactive for SERS [27].

Tian et al. developed SHINERS in 2010 to solve the limitations of the catalyst used in SERS [21]. Figure 3a shows the SHINERS electrode structure and working principle. They synthesized $\mathrm{Au}$ nanospheres coated with pinholefree and ultrathin silica (or alumina) shells. The $\mathrm{Au} / \mathrm{SiO}_{2}$ core/shell nanoparticles were coated onto the substrate adsorbed by probed molecules. The principle is the same as that of tip-enhanced Raman spectroscopy (TERS), in which the Au tip end can provide localized electromagnetic field enhancement, and the probed molecule can borrow the enhancement from the Au tip, as shown in Fig. 3b. In SHINERS, the core-shell nanoparticles act as the TERS tip. The layer of nanoparticles spread over the catalyst electrode provides many TERS tips, resulting in a very strong Raman signal $[19,21,31]$. Furthermore, since silica shell is usually more inactive than the Au surface for many catalytic reactions and intermediate adsorption [21], it can act as a protective layer for the conservation of SERS-active Au core and the inhibition of the interaction between $\mathrm{Au}$ and probed molecules, which is a great advantage of the SHINERS method.

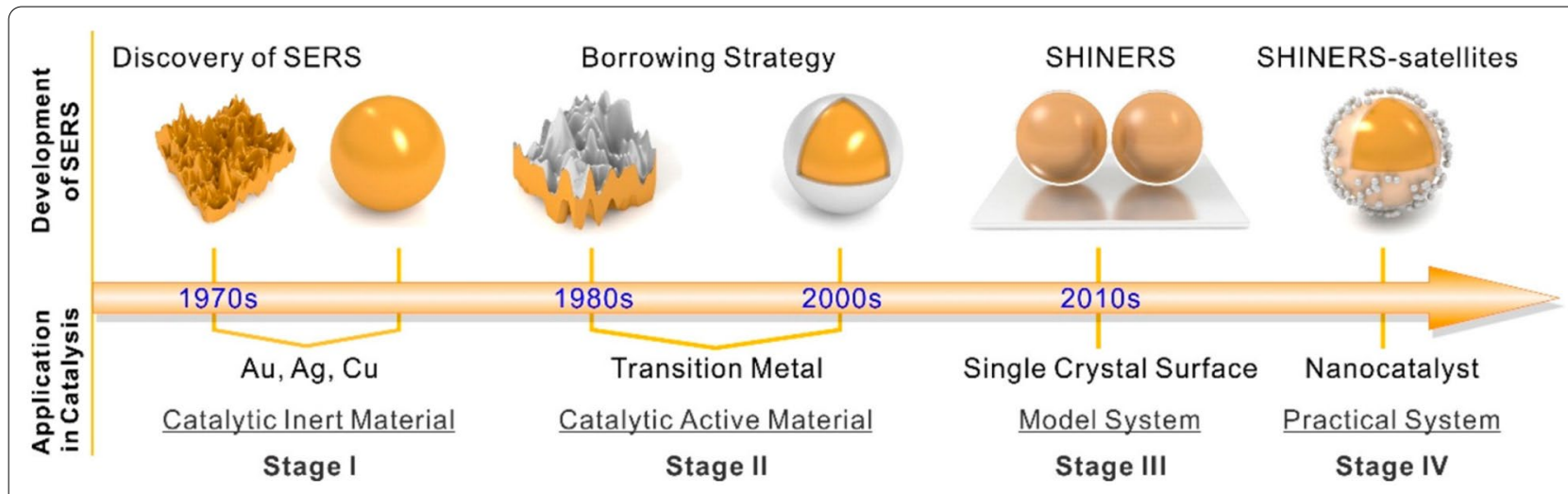

Fig. 2 The historical illustration of surface-enhanced Raman spectroscopy for the catalysis application. Discovery of SERS (stage I), borrowing strategy for non-plasmonic active materials (stage II), application of SHINERS on single crystalline surface as a model system (stage III), and practical system of SHINERS with satellite structure of nanocatalysts (stage IV), reproduced with permission from [27]. Copyright (2020) American Chemical Society 

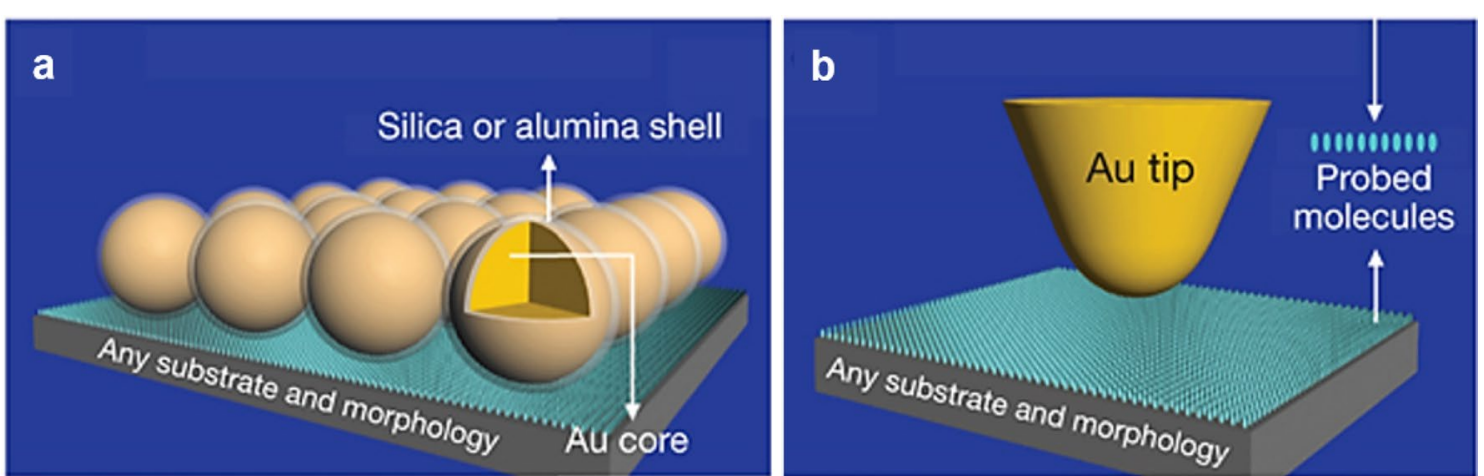

Fig. 3 The comparison between SHINERS working principle with other a shell-isolated mode: SHINERS. b non-contact mode: tip-enhanced Raman spectroscopy, reproduced with permission from [21]. Copyright (2010) Macmillan Publishers Limited

The SHINERS activity is determined by the size of the nanoparticle core and the thickness of the shell. Different sizes of nanoparticles have different extinction spectra and resonance wavelengths under light illumination, which affects the Raman enhancement factor, as shown in Fig. 4a [32, 34, 35]. Fang et al. evaluated the SERS activity of Au nanoparticles with sizes ranging from 16 to $160 \mathrm{~nm}$ that were adsorbed using pyridine as the probe molecule in the absence of a silica shell [33]. Figure $4 b$ shows the SERS spectra of pyridine adsorbed on Au nanoparticles of different sizes. At a diameter of $135 \mathrm{~nm}$, the SERS intensity of $\mathrm{v}_{1}$ pyridine vibration positioned at $1007 \mathrm{~cm}^{-1}$
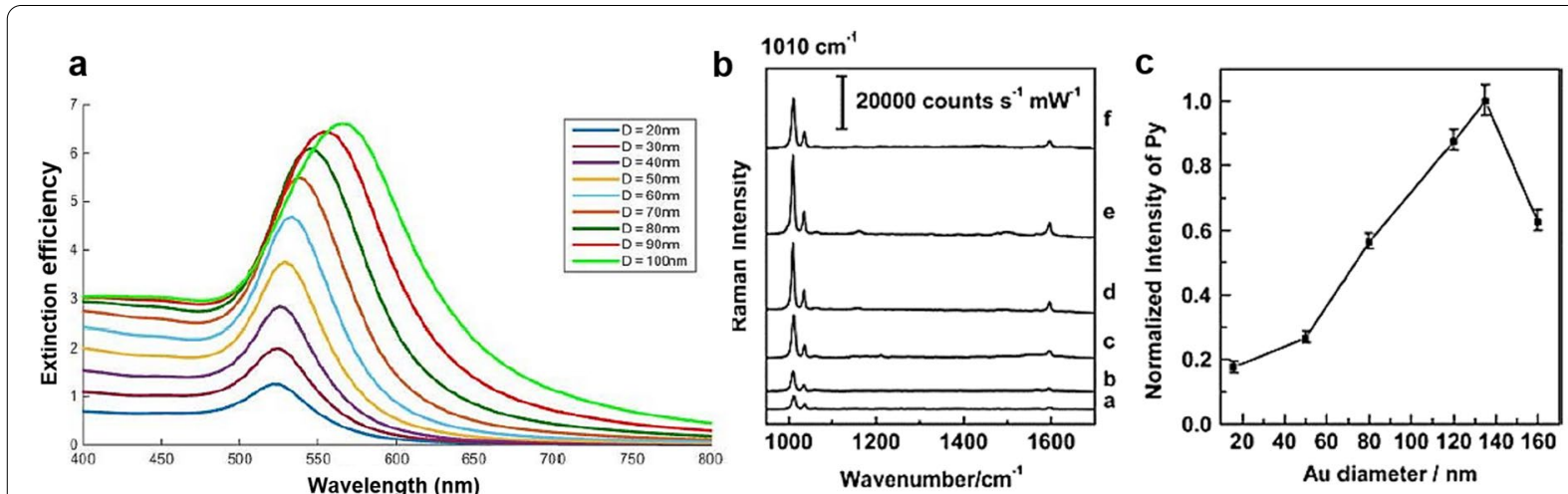

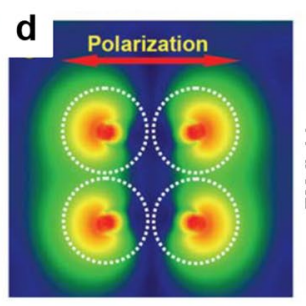

$2 \mathrm{~nm} \mathrm{SiO}$ thickness
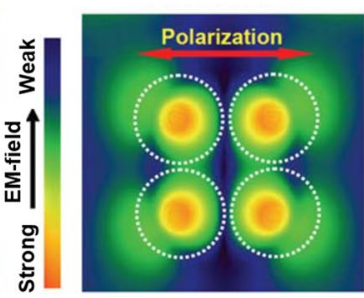

$8 \mathrm{~nm} \mathrm{SiO}$ thickness
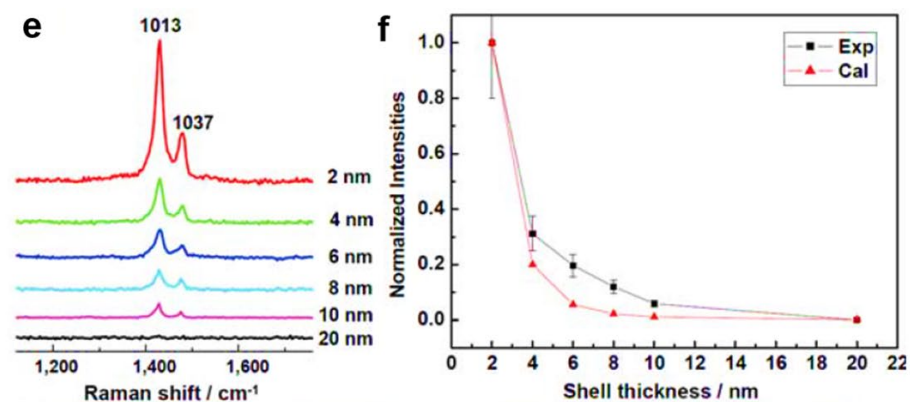

Fig. 4 a The extinction efficiency of Au nanospheres with different diameters, reproduced with permission from [32]. Copyright (2018) IOP Publishing Ltd. b) SERS spectra of pyridine adsorbed on Au nanoparticles with different sizes: 16 to $160 \mathrm{~nm}$ (from a-f). cThe normalized SERS intensity of pyridine as a function of the Au nanoparticle size, reproduced with permission from [33]. Copyright (2008) John Wiley and Sons, Ltd. d The top view of 3D-FDTD simulation from a $2 \times 2$ array of $55 \mathrm{~nm} \mathrm{Au@SiO}$, nanoparticles showing the distribution of electromagnetic field enhancement as a function of shell thickness (the color gradient represents the strength of the electromagnetic field, and the white dash circles indicate the Au@SiO 2 nanoparticles. e SHINERS spectra of pyridine adsorbed on a smooth Au surface coated with Au@SiO 2 with different silica shell thicknesses. $\mathbf{f}$ The dependence of the normalized intensity of pyridine on the shell thickness, reproduced with permission from [21]. Copyright (2010) Macmillan Publishers Limited 
was at its maximum (approximately 32,000 counts $\mathrm{s}^{-1}$ $\mathrm{mW}^{-1}$ ). Figure $4 \mathrm{c}$ shows the relationship between SERS intensity and nanoparticle size. These results show that there is an optimum nanoparticle size that is consistent with the $633 \mathrm{~nm}$ laser excitation wavelength. The resonance wavelength of SERS is widely known to be dependent on the nanoparticle size [36]. Shell thickness also affects the Raman signal enhancement in SHINERS. As shown in the three-dimensional finite-difference timedomain (3D-FDTD) simulation result from a $2 \times 2$ array of $55 \mathrm{~nm} \mathrm{Au@SiO}$ on Au substrate (Fig. 4d), the distribution of electromagnetic field enhancement changes with the thickness of the $\mathrm{SiO}_{2}$ shell [21]. A common trend that electromagnetic field decreases with distance from nanoparticle is observed for 2 and $8 \mathrm{~nm} \mathrm{SiO}{ }_{2}$ thicknesses while stronger field occurs on a broader space in the case of $2 \mathrm{~nm} \mathrm{SiO} 2$ by LSPR [19]. When the $\mathrm{SiO}_{2}$ shell becomes thinner, the distance between the Au core-Au core and Au core-Au substrate decreases. Therefore, the LSPR can be occurred on the junction between Au core-Au core and $\mathrm{Au}$ core-Au substrate, resulting in stronger electromagnetic field enhancement. As a result, the Raman peak intensity of pyridine adsorbed on the smooth $\mathrm{Au} @ \mathrm{SiO}_{2}-$ coated $\mathrm{Au}$ substrate decreases as the $\mathrm{SiO}_{2}$ shell thickness increases (Fig. 4e). Tian's group also plotted the peak intensity of the Raman vibration positioned at $1013 \mathrm{~cm}^{-1}$ (normalized for the signal intensity obtained at $2 \mathrm{~nm}$ thickness) against the shell thickness (Fig. 4f) [21]. This result shows that a thin silica layer is preferred for use in the local electric field from the Au core, provided that a pinhole-free silica layer can be grown.

\section{Synthesis of SHINs}

Since SHINERS was developed, many researchers have tried to examine different shapes of SHINs to further improve the SERS activity of SHINERS. As shown in Fig. 5, nanospheres, nanorod, nanostar, and dipyramids are the synthesized sample shapes. Additionally, different core ( $\mathrm{Au}$ and $\mathrm{Ag})$ and shell $\left(\mathrm{SiO}_{2}\right.$ and $\left.\mathrm{Al}_{2} \mathrm{O}_{3}\right)$ materials were used. In this chapter, various synthetic strategies for preparing different SHINs are explained in detail.

The spherical nanoparticle is the most commonly used shape for SHINERS because of its simple preparation. The Au nanospheres are generally synthesized using the method developed by Turkevich and Frens [40, 41]. In the synthetic method, $\mathrm{HAuCl}_{4}$ solution was first heated, and sodium citrate solution was subsequently added. After the solution color changed to red, the heating was continued for $30 \mathrm{~min}$, and the resultant solution was cooled to room temperature [40]. Sodium citrate acts as a reducing agent and a stabilizing agent to produce monodisperse and uniform Au nanoparticles. Nanosphere particle size

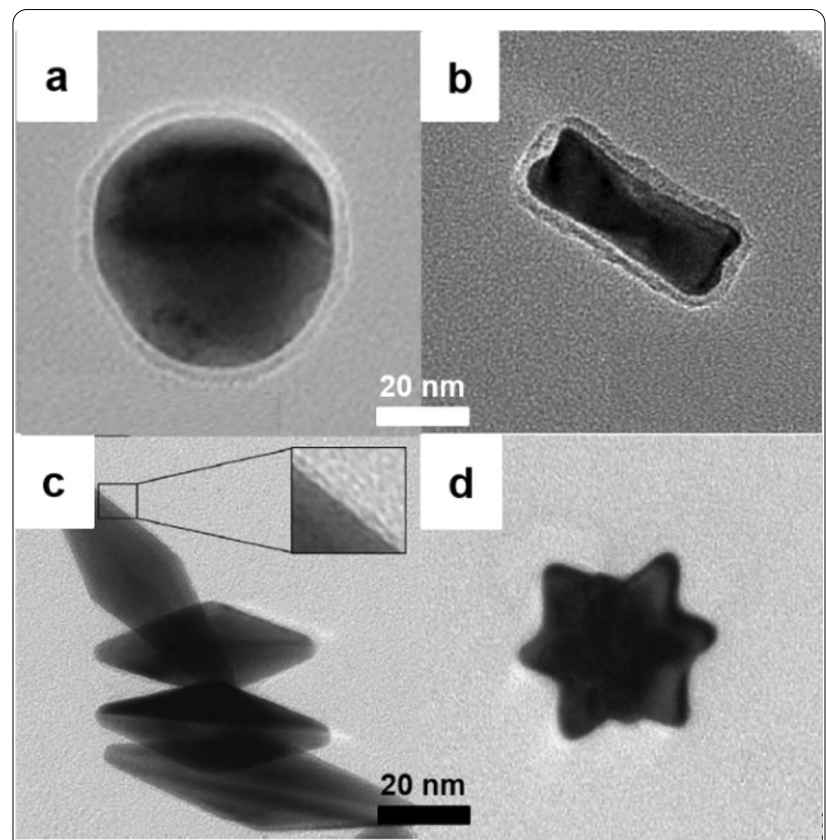

Fig. 5 Different SHIN shapes. a Nanosphere, reproduced with permission from [21]. Copyright (2010) Macmillan Publishers Limited. b Nanorod, reproduced with permission from [37]. Copyright (2011)

Oldenbourg Wissenschaftsverlag. c Nanodipyramid, reproduced with permission from [38]. Copyright (2018) Elsevier. d Nanostar, reproduced with permission from [39]. Copyright (2019) Elsevier

can be controlled by adjusting the amount of sodium citrate. If the amount of sodium citrate is reduced, the size of the nanosphere would be small [41].

Nanorods have been widely used in SERS activity control [37]. Au nanorod was first synthesized based on a method by Sau and Murphy [42]. The $\mathrm{HAuCl}_{4}$ was mixed with cetyltrimethylammonium bromide (CTAB), which served as a shape-controlling agent for the gold nanoparticle. Next, $\mathrm{NaBH}_{4}$ solution, a reducing agent, was added while stirring, and the solution had a pale brown-yellow color. The seed solution was then added to the growth solution consisting of $\mathrm{AgNO}_{3}, \mathrm{CTAB}$, and $\mathrm{HAuCl}_{4}$. The $\mathrm{Ag}^{+}$ions serve as sacrificial ions, allowing for the reduction of $\mathrm{Au}^{3+}$ ions to form $\mathrm{Au}$ nanorods. Afterward, (3-aminopropyl)trimethoxysilane (APTMS) solution was added to the nanorod solution while stirring, and sodium silicate was added for $\mathrm{SiO}_{2}$ layer coating [37]. Quyen et al. demonstrated that the Raman intensity of rhodamine $6 \mathrm{G}$ captured with a rod-shaped $\mathrm{Au} @ \mathrm{SiO}_{2}$ as the SERS material was more than 3 times higher than that captured with spherical-shaped $\mathrm{Au} @ \mathrm{SiO}_{2}$ [43]. The signal enhancement was attributed to the different photophysical property of $\mathrm{Au} @ \mathrm{SiO}_{2}$ nanorods. It had a long-wavelength band in the near-infrared region with a high absorption intensity. 
Sharp edges are known for increasing the electromagnetic field surrounding plasmonic materials because of their high electron density [51-54]. Kudelski's group developed dipyramidal-shaped $\mathrm{Au} @ \mathrm{SiO}_{2}$ nanoparticles to increase the efficiency of Raman signal enhancement in SHINERS [38]. Dipyramidal gold was synthesized by growing pyramids on gold nanoparticle seeds with two key factors: $\mathrm{pH}$ and $\mathrm{Ag}^{+}$concentration. A solution with a low $\mathrm{pH}$ is required to increase the redox potential of ascorbic acid. In this condition, an Ag monolayer can be deposited on the gold nanoparticle surface, stabilizing it and inhibiting tip growth. When using a high $\mathrm{pH}$, the $\mathrm{Au}^{3+}$ reduction rate increased, resulting in fast deposition along the crystal face and short aspect ratio nanorod development in all directions [55]. Raman spectra of 4-mercaptobenzoic acid (MBA) and 2-mercaptoethanesulfonate (MES) were examined on a platinum surface covered with dipyramidal shaped Au nanoparticles and spherical shaped Au nanoparticles for Raman intensity enhancement. In comparison with spherical-shaped $\mathrm{Au}$ nanoparticles, dipyramidal-shaped Au showed a significant enhancement in Raman intensity of about 11 and 16 times for MBA and MES, respectively.

In a similar context, Krajczewski et al. synthesized a star-shaped silica-coated gold nanoparticle with a higher number of edges $[39,56]$. They used $\mathrm{HAuCl}_{4}$ as a gold precursor, $\mathrm{H}_{2} \mathrm{O}_{2}$ as a reducing agent, and $\mathrm{NaOH}$ to trigger the reduction reaction and stabilize the gold nanostar nanoparticle. Tetraethyl orthosilicate (TEOS) was used as a silica source for $\mathrm{SiO}_{2}$ coating. The $\mathrm{SiO}_{2}$ shell growth was controlled by the adjusting reaction time; a $15-\mathrm{min}$ reaction time resulted in a 2-4 $\mathrm{nm}$ thick layer. The same group also compared the Raman enhancement efficiency of MBA monolayers on the Pt surface covered with $\mathrm{Au}$ nanostar and spherical $\mathrm{Au}$ nanoparticles using SERS spectra. The Raman spectra obtained by MBA using Au nanostar as SERS probe were enhanced more than 10 times when compared to spherical Au nanoparticles [39].

Although $\mathrm{Au}$ metal is widely used as a core nanoparticle in SHINERS, other metals with high plasmonic characteristics, such as Ag, can also be used. Tian's group synthesized Ag nanospheres with Au seeds because Ag has a tendency to be oxidized, and this resulted in the formation of anisotropic nanoparticles [57]. Ascorbic acid was used to reduce the $\mathrm{Ag}^{+}$ions on the $\mathrm{Au}$ seed surfaces. The polyol method has also been used to synthesize silver nanowires. In this method, ethylene glycol is used as a solvent and reducing agent. Polyvinylpyrrolidone acts as a capping agent, regulating the growth rate of silver nanowires [58]. Although Ag is more easily oxidized and mobile than $\mathrm{Au}$, it is significantly less expensive and has a higher surface plasmon efficiency than Au. Tian et al. observed that the enhancement effect of the pyridine Raman intensity in $\mathrm{Ag} @ \mathrm{SiO}_{2}$ nanoparticles was 100 times higher than that in $\mathrm{Au} @ \mathrm{SiO}_{2}$ [57].

The plasmonic core in the SHINERS was coated with an ultrathin metal oxide shell, such as $\mathrm{SiO}_{2}$ and $\mathrm{Al}_{2} \mathrm{O}_{3}$. For silica coating, APTMS solution was added to the solution of $\mathrm{Au}$ or $\mathrm{Ag}$ nanoparticles under vigorous stirring. The APTMS caused the Au nanoparticle surface to generate silanol functional groups, which are responsive to silicate ion deposition [59,60]. Subsequently, a sodium silicate solution with a $\mathrm{pH}$ of 10.2 was added to the mixture. One of the important parameters for $\mathrm{SiO}_{2}$ shell growth is $\mathrm{pH}$ regulation. If the $\mathrm{pH}$ of sodium silicate is higher than 11, shell dissolution by $\mathrm{NaOH}$ will obstruct its growth, resulting in the detection of a pinhole. If a lower $\mathrm{pH}(\mathrm{pH} 8)$ is used, the $\mathrm{SiO}_{2}$ shell will rapidly grow and become excessively thick.

The reaction temperature is another key parameter that must be controlled. Tian's group used a $90{ }^{\circ} \mathrm{C}$ water bath for $\mathrm{SiO}_{2}$ shell growth instead of the typically used room temperature [21]. The elevated temperature can reduce the reaction time from 48 or $72 \mathrm{~h}$ to just $1 \mathrm{~h}$ for producing $\mathrm{SiO}_{2}$ with a $4 \mathrm{~nm}$ shell thickness. The thickness of the silica shell can be delicately adjusted by controlling the reaction time. For example, a $2 \mathrm{~nm}$ shell thickness can be achieved by heating the mixture for $20 \mathrm{~min}$, whereas thicker shells of 4 and $6 \mathrm{~nm}$ can be obtained by extending the reaction time to 1 and $2 \mathrm{~h}$, respectively.

The atomic layer deposition (ALD) method can also be used to prepare ultrathin SHIN shells. In summary, the ALD method is used to coat Au core nanoparticles by sequentially purging the shell precursor gas, resulting in layer-by-layer growth with high uniformity. This method has been widely used to fabricate metal oxide shells, such as $\mathrm{Al}_{2} \mathrm{O}_{3}$ and $\mathrm{TiO}_{2}$ shells, which can be ultrathin and uniform without a pinhole [61]. Zhang et al. used the ALD method to obtain a large quantity of SHINs $(1-10 \mathrm{~g})$ with uniform shells by floating metal nanoparticles in a chamber via gas flow [62].

Noble metals such as $\mathrm{Pt}, \mathrm{Pd}, \mathrm{Rh}$, and $\mathrm{Ru}$ are known to be inactive for SERS but catalytically active. Coating those metals on the plasmonically-active material also can be a way to probe the catalyst surface by constructing a plasmonic-catalytic hybrid nanoreactor. Acharya et al. applied plasmon-induced photocatalytic ALD to deposit atomically thin catalytic-active metal on the Au nanorod surface [63]. Firstly, the gold nanorod was individually isolated with a hollow silica shell. For catalytically-active metal coating, the hollow silica-coated Au nanorod dispersion was mixed with metal salt in ethylene glycol (EG) and irradiated with a near-infrared (NIR) laser with a power density of $0.4 \mathrm{~W} / \mathrm{cm}^{2}$ at $35{ }^{\circ} \mathrm{C}$. EG was used to control the metal shell growth around the Au nanorod surface. If stronger reducing agents such as ascorbic acid 
or hydroxylamine were used, a dendritic shape metal growth would be resulted instead of the conformal metal coating.

\section{SHINERS application}

SHINERS has been used to gain mechanistic insights into various electrochemical reactions, including HER $[21,44]$, ORR [20, 48], CO reduction reaction (CORR) $[15,47]$, CO oxidation reaction (COOR) $[64,65], \mathrm{CO}$ adsorption [44], OER [46], and $\mathrm{NO}_{3} \mathrm{RR}$ [50]. Table 1 summarizes the applications of SHINERS in the electrocatalysis research field, as well as the detailed experimental conditions, such as SHINs, electrode, electrolyte, and laser wavelength. According to previous studies, SHINERS has proven to be a powerful method for probing intermediate species that are rarely detected. For example, SHINERS can be used to monitor the vibrational modes of the binding of an atom and a smooth metal electrode with a low SERS activity (e.g., $\mathrm{Pt}(111)-\mathrm{H}$ and $\mathrm{Rh}(111)-\mathrm{H})$ regardless of the type of metal substrate [21, 44]. The vibrational information obtained by SHINERS could be used to provide further insight into enhanced activities of high-performance electrocatalysts, provided that the binding strength of key intermediates at the catalyst surface has a strong correlation with the catalytic activity based on the Sabatier principle $[9,66]$. Furthermore, SHINERS can be applied to a particular metal oxide film, such as electrodeposited iridium oxide $\left(\mathrm{IrO}_{\mathrm{x}}\right)$ film [46]. This study demonstrated a highly sensitive detection of an $\mathrm{Ir}=\mathrm{O}$ stretching mode near the onset potential of the OER. In this regard, SHINERS has great potential for the mechanistic investigation of electrocatalysis, and its applications should be discussed in detail. In this chapter, we discuss several case studies in which the SHINERS technique was used to observe surface chemical species for ORR, CORR, COOR, OER, and $\mathrm{NO}_{3} \mathrm{RR}$. The proposed reaction mechanisms and reaction pathways are discussed in detail based on the SHINERS results.

Table 1 Summary of reported applications and experimental conditions of SHINERS for electrocatalyst

\begin{tabular}{|c|c|c|c|c|c|c|c|c|}
\hline Ref. & Core metal & Shell & Electrode & Electrolyte & $\begin{array}{l}\text { Laser } \\
\text { wavelength } \\
(\mathrm{nm})\end{array}$ & Vibrational mode & $\begin{array}{l}\text { Wavenumber } \\
\left(\mathrm{cm}^{-1}\right)\end{array}$ & Application \\
\hline [21] & $\mathrm{Au}$ & $\begin{array}{l}\mathrm{SiO}_{2} \\
\mathrm{Al}_{2} \mathrm{O}_{3}\end{array}$ & $\operatorname{Pt}(111)$ & $0.1 \mathrm{~m} \mathrm{NaClO}_{4}$ & 632.8 & $\mathrm{Pt}-\mathrm{H}$ & 2023 & Hadsorption \\
\hline$[44]$ & $\mathrm{Au}$ & $\mathrm{SiO}_{2}$ & $\operatorname{Rh}(111)$ & $0.1 \mathrm{~m} \mathrm{NaClO}_{4}$ & 633 & $\mathrm{Rh}-\mathrm{H}$ & 1897 & Hadsorption \\
\hline$[45]$ & $\mathrm{Au}$ & $\mathrm{SiO}_{2}$ & $\begin{array}{l}\text { Pt (111) } \\
\text { Pt polycrystalline }\end{array}$ & $\begin{array}{l}0.1 \mathrm{~m} \mathrm{HClO}_{4} \text { saturated } \\
\text { by } \mathrm{CO}\end{array}$ & 632.8 & $\mathrm{Pt}-\mathrm{CO}$ & 2071 & CO adsorption \\
\hline$[46]$ & $\mathrm{Au}$ & $\mathrm{SiO}_{2}$ & $\operatorname{lrOx}$ & $1 \mathrm{~m} \mathrm{NaClO}_{4}(\mathrm{pH} 10)$ & 632.8 & $\mathrm{Ir}=\mathrm{O}$ stretching & 813 & OER \\
\hline & $\mathrm{Au}$ & $\mathrm{SiO}_{2}$ & $\begin{array}{l}\text { Cu foil } \\
\text { Cu microparticles }\end{array}$ & $\begin{array}{l}0.01 \mathrm{~m} \mathrm{KOH} \text { and } \\
0.046 \mathrm{~m} \mathrm{~K}_{2} \mathrm{SO}_{4}(\mathrm{pH} 11.7)\end{array}$ & 632.8 & $\mathrm{Cu}-\mathrm{O}_{(\mathrm{ad})}$ & $612-622$ & CO reduction \\
\hline$[15]$ & & & $\begin{array}{l}\text { Cu Nanoparticle } \\
\text { Chem-Cu } \\
\text { Oxide derived } \mathrm{Cu}\end{array}$ & & & $\begin{array}{l}\mathrm{Cu}-\mathrm{CO}_{(\text {bridge })} \\
\mathrm{Cu}-\mathrm{CO}_{(\text {top })}\end{array}$ & $\begin{array}{l}1863-1873 \\
2053-2070\end{array}$ & \\
\hline$[47]$ & $\mathrm{Au}$ & $\mathrm{SiO}_{2}$ & $\begin{array}{l}\text { Cu dendritic micropar- } \\
\text { ticles }\end{array}$ & $\begin{array}{l}0.3 \mathrm{~m} \mathrm{NaH}_{2} \mathrm{PO}_{4} \text { and } \\
0.35 \mathrm{~m} \mathrm{Na}_{2} \mathrm{HPO}_{4}(\mathrm{pH} \\
\text { 7.2) }\end{array}$ & 632.8 & $\mathrm{CuO}_{x} /(\mathrm{OH})_{y}$ & $525-532$ & CO reduction \\
\hline & & & & $\begin{array}{l}0.1 \mathrm{~m} \mathrm{NaOH} \text { and } 0.9 \mathrm{~m} \\
\mathrm{NaClO}_{4}(\mathrm{pH} 12.9)\end{array}$ & & Cu-phosphate & $931,1124-1152$ & \\
\hline$[48]$ & $\mathrm{Au}$ & $\mathrm{SiO}_{2}$ & $\begin{array}{l}\text { Pd } \\
\text { Pt }\end{array}$ & $\begin{array}{l}0.1 \mathrm{~m} \mathrm{TBAClO}_{4} \text { in } \mathrm{DMSO} \\
\text { saturated by } \mathrm{O}_{2}\end{array}$ & 785 & $\begin{array}{l}\mathrm{O}-\mathrm{O}-\text { in } \mathrm{LiO}_{2} \\
\mathrm{C}-\mathrm{O}_{2}-\text { in } \mathrm{CO}_{2} \mathrm{Li}\end{array}$ & $\begin{array}{l}1125 \\
1500\end{array}$ & ORR \\
\hline [49] & $\mathrm{Au}$ & $\mathrm{SiO}_{2}$ & $\begin{array}{l}\operatorname{Pt}(100) \\
\operatorname{Pt}(111)\end{array}$ & $0.1 \mathrm{~m} \mathrm{HClO} 4$ & 632.8 & $\begin{array}{l}\mathrm{Pt}-\mathrm{O}_{2} \text { stretching } \\
\mathrm{O}-\mathrm{O}^{-} \\
\mathrm{O}-\mathrm{O}^{2-}\end{array}$ & $\begin{array}{l}240 \\
970 \\
1200\end{array}$ & Pt electrooxidation \\
\hline$[50]$ & $\mathrm{Au}$ & $\mathrm{SiO}_{2}$ & $\begin{array}{l}\mathrm{Cu}(100) \\
\mathrm{Cu}(110) \\
\mathrm{Cu}(111)\end{array}$ & $\begin{array}{l}0.1 \mathrm{~m} \mathrm{HClO}_{4} \text { and } 0.05 \mathrm{~m} \\
\mathrm{HNO}_{3} \\
0.1 \mathrm{~m} \mathrm{HClO}_{4}, 0.05 \mathrm{~m} \\
\mathrm{HNO}_{3} \text {, and } 10 \mathrm{~mm} \mathrm{HCl}\end{array}$ & 632.8 & $\begin{array}{l}\mathrm{Cu}_{2} \mathrm{O} \text { in } \mathrm{Cu}(110) \\
\mathrm{Cu}_{2} \mathrm{O} \text { in } \mathrm{Cu}(110)\end{array}$ & $\begin{array}{l}509,619 \\
502,621\end{array}$ & Nitrate reduction \\
\hline$[20]$ & $\mathrm{Au}$ & $\mathrm{SiO}_{2}$ & $\begin{array}{l}\operatorname{Pt}(100) \\
\operatorname{Pt}(110) \\
\operatorname{Pt}(111)\end{array}$ & $\begin{array}{l}0.1 \mathrm{~m} \mathrm{HClO}_{4} \text { saturated } \\
\text { by } \mathrm{O}_{2} \\
0.1 \mathrm{~m} \mathrm{NaClO}_{4} \text { saturated } \\
\text { by } \mathrm{O}_{2}(\mathrm{pH} 10.3)\end{array}$ & 637.8 & $\begin{array}{l}\mathrm{Pt}-\mathrm{COOH} \\
\mathrm{Pr}-\mathrm{OH}\end{array}$ & $\begin{array}{l}1005 \\
1090\end{array}$ & ORR \\
\hline
\end{tabular}




\section{Oxygen reduction reaction}

The ORR is a cathodic reaction in fuel cells. The ORR catalyst must remain stable under extremely corrosive conditions [67]. Platinum-based nanocatalysts have been studied as ORR catalysts, but the structural effect of Ptbased catalysts on the ORR mechanism has not been well understood based on experimental results [68].

Dong et al. investigated the ORR process at $\mathrm{Pt}(\mathrm{hkl})$ surfaces in both acidic and alkaline conditions [20]. The direct evidence of intermediate species that occurred during the ORR process was captured using the SHINERS method. Figure 6a shows the SHINERS spectra of the ORR with the $\mathrm{Pt}(111)$ electrode obtained in acidic conditions on a potential range of 1.1-0.5 V. There was no Raman signal peak recorded above $0.8 \mathrm{~V}$, except for the symmetric stretching mode of $\mathrm{ClO}_{4}^{-}$ion at $933 \mathrm{~cm}^{-1}$. A Raman peak around $732 \mathrm{~cm}^{-1}$ appeared at $0.8 \mathrm{~V}$ and gradually increased as the potential reached $0.5 \mathrm{~V}$. The peak was assigned to the $\mathrm{O}-\mathrm{O}$ stretching vibration of $\mathrm{OOH}^{*}$ based on isotopic substitution experiments and density-functional theory (DFT) calculations. Conversely, the Raman spectra were noticeably different in the case of the $\mathrm{Pt}(100)$ and (110) surfaces. There were two Raman peaks recorded at 1030 and $1080 \mathrm{~cm}^{-1}$, which were assigned to the vibrational modes of $\mathrm{ClO} 3$ and $\mathrm{OH}^{*}$, respectively (Fig. $6 \mathrm{~b}$ and c). The SEM image of the SHINs-modified electrode surface used in the experiment is shown in Fig. 6d.

According to previous studies, several intermediates, such as $\mathrm{O}^{*}$, $\mathrm{OOH}^{*}, \mathrm{O}^{*}$, and $\mathrm{OH}^{*}$, are involved in ORR via four coupled proton-electron transfers, as shown below $[12,22]$ :

$$
\begin{aligned}
& \mathrm{O}_{2}+* \rightarrow \mathrm{O}_{2} * \\
& \mathrm{O}_{2} *+\mathrm{H}^{+} \mathrm{e}^{-} \rightarrow \mathrm{OOH} *
\end{aligned}
$$
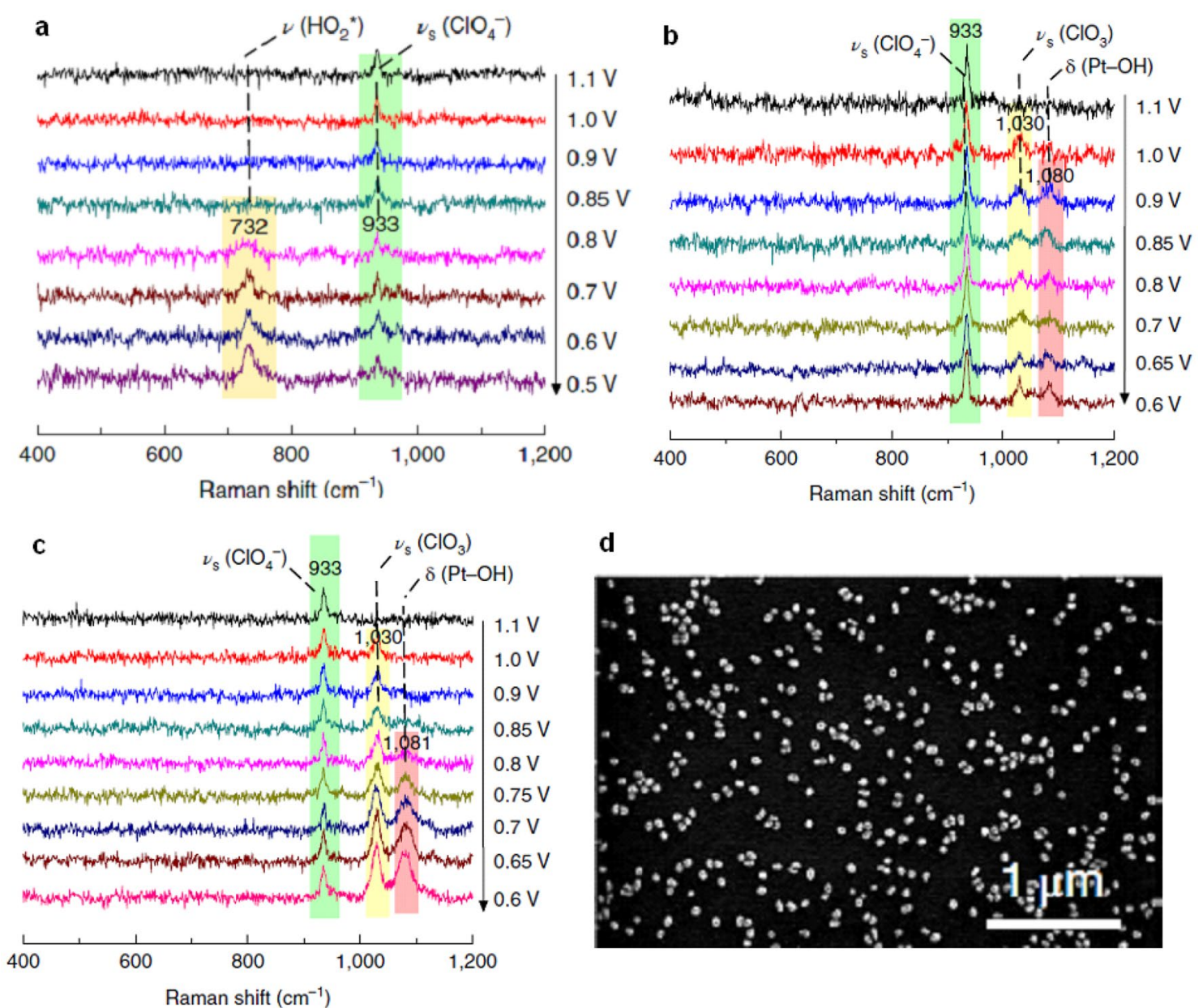

d

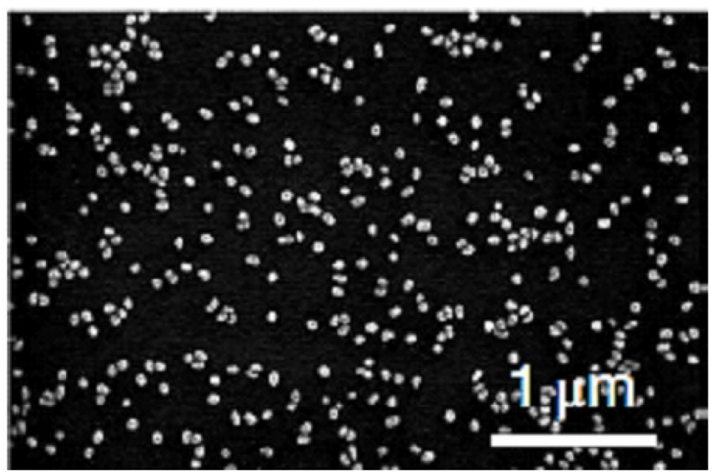

Fig. 6 SHINERS of the ORR in a $0.1 \mathrm{M} \mathrm{HClO}_{4}$ solution saturated with $\mathrm{O}_{2}$ at the a Pt(111) electrode surface, $\mathbf{b}$ Pt(100) electrode surface, and $\mathbf{c}$ $\mathrm{Pt}(110)$ electrode surface, $\mathbf{d}$ The scanning electron microscopy (SEM) images of a Pt(111) single-crystal electrode surface modified with Au@SiO reproduced with permission from [20]. Copyright (2018) Springer Nature Limited 


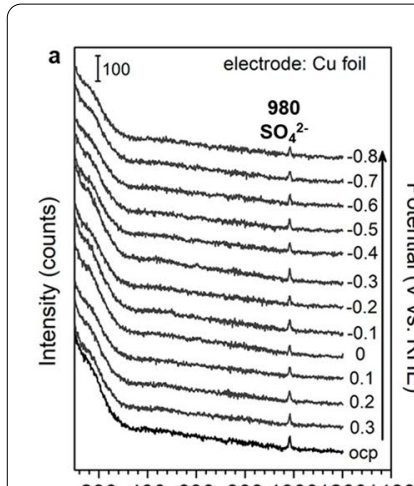

200400600800100012001400 Raman shift $\left(\mathrm{cm}^{-1}\right)$

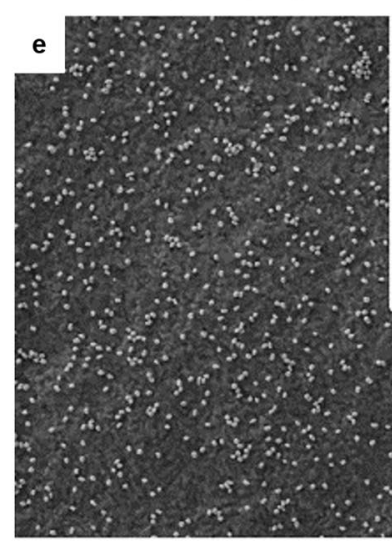

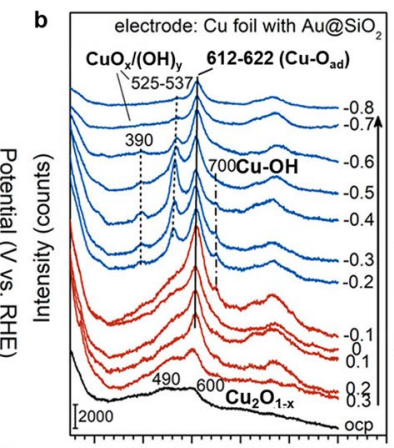

200400600800100012001400 Raman shift $\left(\mathrm{cm}^{-1}\right)$

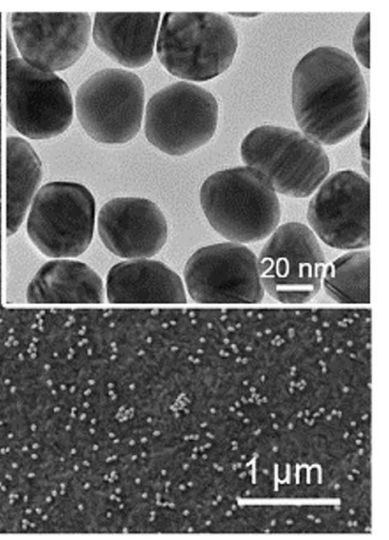

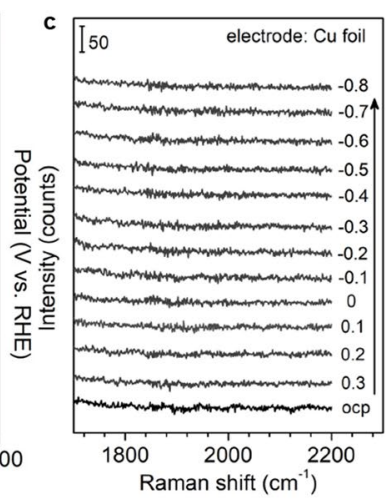
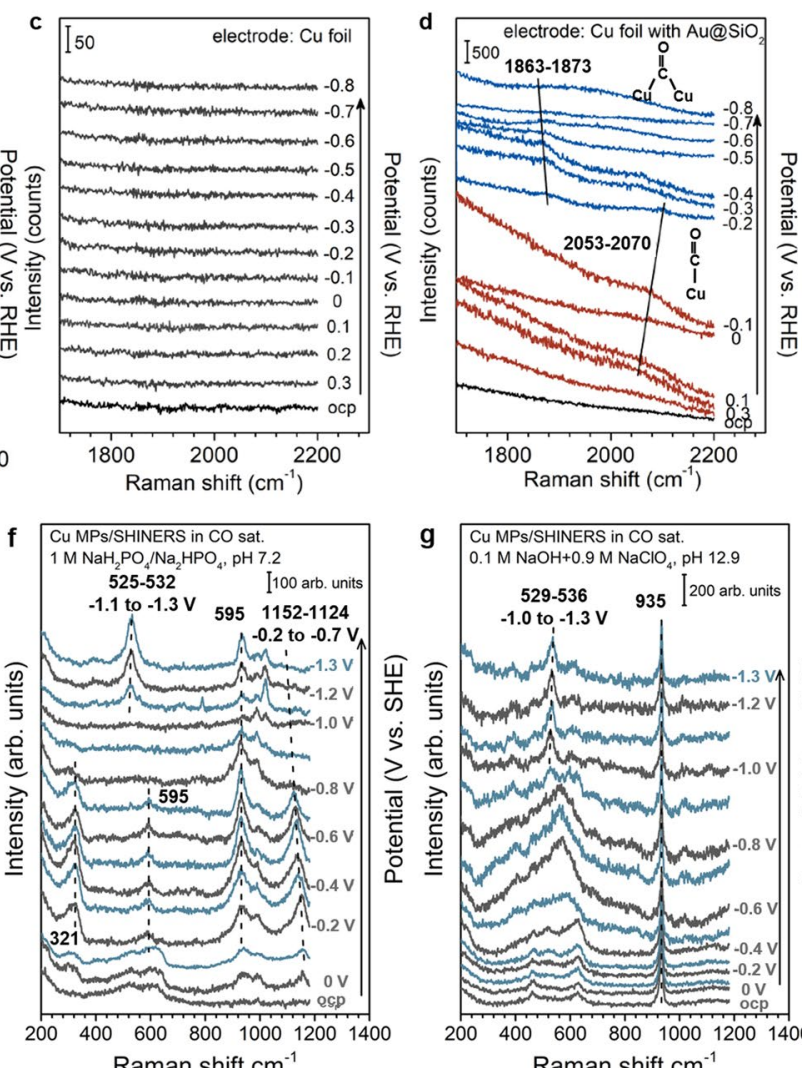

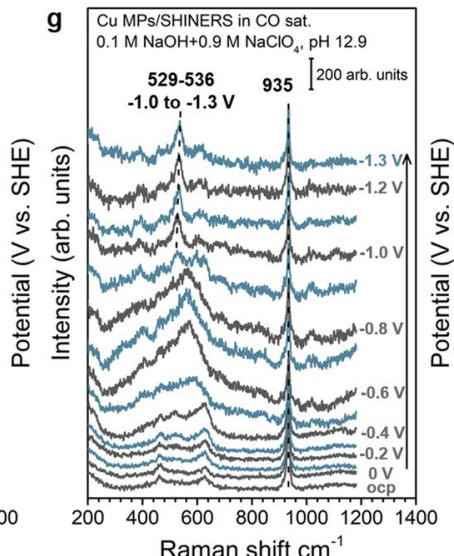

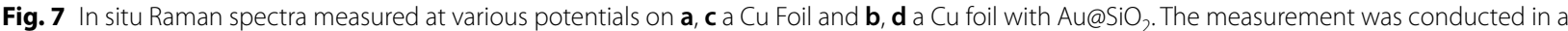
CO-saturated electrolyte to probe the surface species during CORR (0.01 M KOH and $\left.0.045 \mathrm{M} \mathrm{K}_{2} \mathrm{SO}_{4}, \mathrm{pH} 11.7\right)$, e SEM image of Cu foil with Au@SiO 2 (inset image: TEM image of Au@SiO 2 ) reproduced with permission from [15]. Copyright (2020) American Chemical Society. In situ Raman spectra measured at various potentials on $\mathbf{f}$ Cu microparticle in CO-saturated $0.3 \mathrm{M} \mathrm{NaH}_{2} \mathrm{PO}_{4} / 0.35 \mathrm{M} \mathrm{Na}_{2} \mathrm{HPO}_{4}(\mathrm{pH} 7.2)$. g Cu microparticle in CO-saturated $0.1 \mathrm{M} \mathrm{NaOH} / 0.9 \mathrm{M} \mathrm{NaClO}_{4}(\mathrm{pH}$ 12.9), reproduced with permission from [47]. Copyright (2021) Springer Nature

$$
\begin{aligned}
& \mathrm{OOH} *+\mathrm{H}^{+}+\mathrm{e}^{-} \rightarrow \mathrm{O} *+\mathrm{H}_{2} \mathrm{O} \\
& \mathrm{O} *+\mathrm{H}^{+}+\mathrm{e}^{-} \rightarrow \mathrm{OH} * \\
& \mathrm{OH}^{*}+\mathrm{H}^{+}+\mathrm{e}^{-} \rightarrow \mathrm{H}_{2} \mathrm{O}+*
\end{aligned}
$$

The dissociation reaction of $\mathrm{OOH}^{*}$, in particular, is known as the rate-limiting step. The $\mathrm{OOH}^{*}$ species was not stable on the $\mathrm{Pt}(110)$ and $\mathrm{Pt}(100)$ surfaces because it dissociated easily into $\mathrm{O}^{*}$ and $\mathrm{OH}^{*}$, which was also supported by DFT calculations [20]. Therefore, the difference in the ORR activity between the $\mathrm{Pt}(111)$ and $\mathrm{Pt}(110)$ and (100) surfaces can be attributed to the difference in the $\mathrm{OOH}^{*}$ dissociation. The Tian group also investigated the ORR process on $\mathrm{Pt}$ (211) and (311) surfaces with different applied potentials. They discovered two peaks that appeared at 786 and $1042 \mathrm{~cm}^{-1}$ after the potential reached $0.9 \mathrm{~V}$ and further confirmed that the two peaks were from $\mathrm{OOH}^{*}$ and $\mathrm{OH}^{*}$, respectively, demonstrating that high-index facets of Pt metals have different intermediate adsorption features [69].

\section{Carbon monoxide reduction reaction}

$\mathrm{CO}$ is an important chemical that is used as a precursor in the pre-existing petrochemical industry and recent electrochemical conversion research because of its ability to be converted into valuable hydrocarbons and alcohols, such as methane, methanol, and ethanol. Copper is a promising candidate for the electrochemical reduction reaction of $\mathrm{CO}$, but the surface chemical species of $\mathrm{Cu}$ electrodes and its role in enhancing the CORR are still unclear [15].

As shown in Fig. 7, Zhao et al. used SHINERS to unravel the surface species on $\mathrm{Cu}$ foils with and without $\mathrm{Au} @ \mathrm{SiO}_{2}$ during the reaction [15]. The in situ Raman spectra recorded without $\mathrm{Au} @ \mathrm{SiO}_{2}$ (Fig. 7a and c) showed no Raman signals from the $\mathrm{Cu}$ foil in the examined potential range of open circuit potential (OCP) to $-0.8 \mathrm{~V}$ in the $\mathrm{CO}$ saturated electrolyte, except for a 


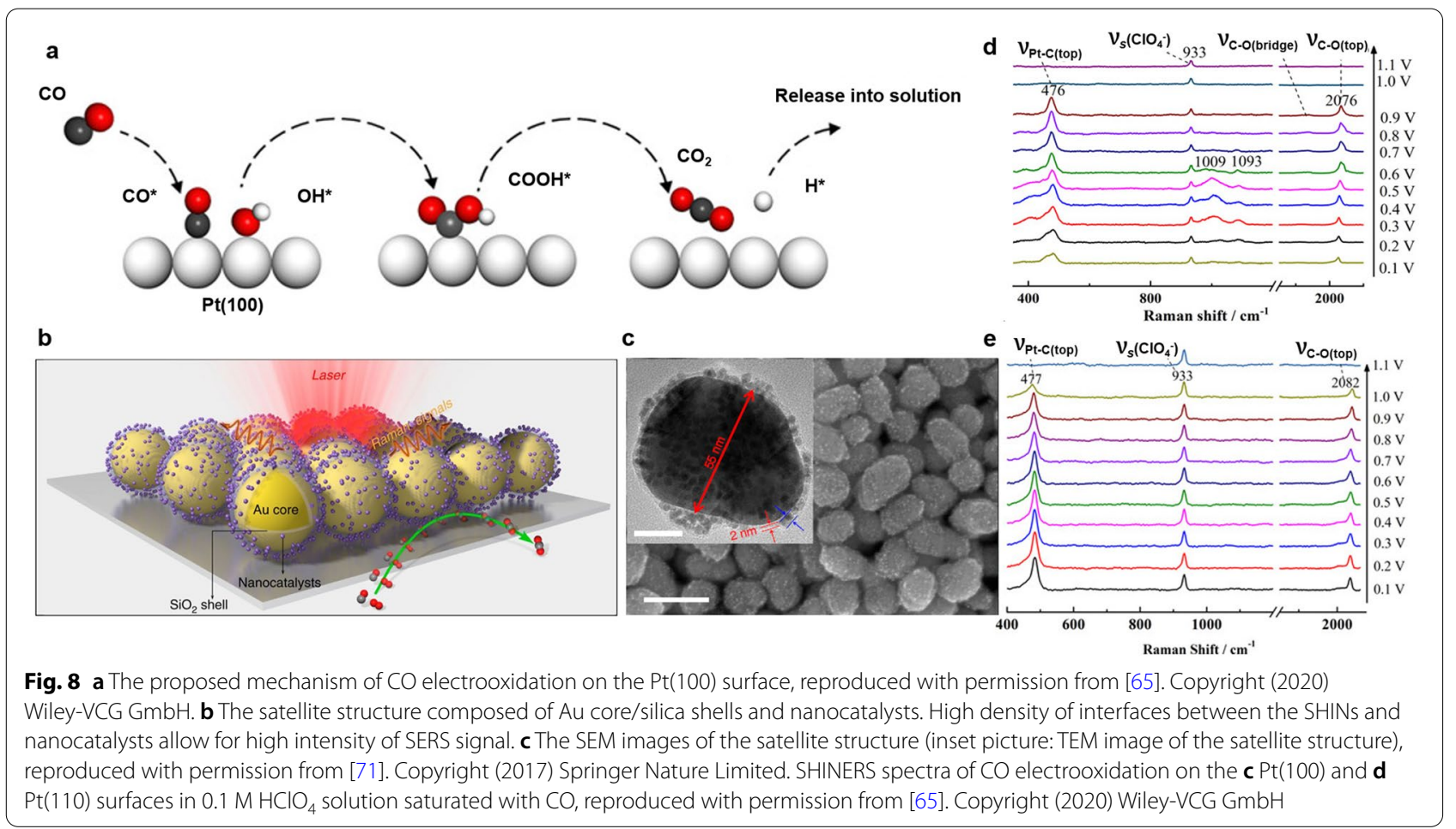

sulfate ion peak at $980 \mathrm{~cm}^{-1}$ originating from the electrolyte. However, the in situ Raman spectra recorded in the presence of $\mathrm{Au} @ \mathrm{SiO}_{2}$ (Figs. 7b and d) revealed multiple surface species related to $\mathrm{Cu}$. At the OCP, two broad bands occurred at 490 and $600 \mathrm{~cm}^{-1}$ and were assigned to the partially reduced $\mathrm{Cu}_{2} \mathrm{O}$ phase $\left(\mathrm{Cu}_{2} \mathrm{O}_{1-\mathrm{x}}\right)$. At a more negative potential, a peak appeared at $612-$ $622 \mathrm{~cm}^{-1}$. They confirmed that the peak corresponded to $\mathrm{Cu}-\mathrm{O}_{\text {ad }}$ because there was no peak shifting from the isotopic substitution of $\mathrm{H}_{2} \mathrm{O}$ with $\mathrm{D}_{2} \mathrm{O}$ [15]. Additionally, as shown in Fig. 7d, there were additional peaks from the adsorbed $\mathrm{CO}$ on the $\mathrm{Cu}$ surface. These results demonstrate that SHINERS not only provide information on surface intermediates but also aid in the monitoring of phase evolution of catalyst surfaces during electrochemical reactions. The SEM image of $\mathrm{Cu}$ foil decorated with $\mathrm{Au} @ \mathrm{SiO}_{2}$ is shown in Fig. 7e. The inset picture is a TEM image of $\mathrm{Au} @ \mathrm{SiO}_{2}$ with a shell thickness of $\sim 2 \mathrm{~nm}$.

Meanwhile, Li et al. used SHINERS to investigate the effect of electrolytes on surface species and active sites on dendritic $\mathrm{Cu}$ microparticles [47]. Figure $7 \mathrm{f}-\mathrm{g}$ show in situ Raman spectra of CO-saturated $0.3 \mathrm{M} \mathrm{NaH}_{2} \mathrm{PO}_{4} / 0.35 \mathrm{M}$ $\mathrm{Na}_{2} \mathrm{HPO}_{4}$ and CO-saturated $0.1 \mathrm{M} \mathrm{NaOH} / 0.9 \mathrm{M} \mathrm{NaClO}_{4}$. The author kept the sodium cation concentration $(1 \mathrm{M})$ constant in all electrolyte compositions to avoid the cation effect in CORR activity comparison. Broad Raman bands at 528 and $618 \mathrm{~cm}^{-1}$ assigned to the $\mathrm{Cu}_{2} \mathrm{O}$ surface appeared at the OCP and in the phosphate-containing electrolyte and gradually decreased at increasingly negative potentials. At the potential region between -0.2 and $-0.7 \mathrm{~V}$ vs. SHE, a weak band corresponding to $\mathrm{Cu}-\mathrm{O}_{\mathrm{ad}}$ was observed at $595 \mathrm{~cm}^{-1}$. At potentials below $-1.1 \mathrm{~V}$ vs. SHE, a Raman band assigned to a $\mathrm{CuO}_{\mathrm{x}} /(\mathrm{OH})_{\mathrm{y}}$ mixedphase appeared at $\sim 530 \mathrm{~cm}^{-1}$. Additionally, two different bands (931 and $1152 \mathrm{~cm}^{-1}$ ) assigned to phosphates were identified at potentials below $-0.2 \mathrm{~V}$ vs. SHE. Interestingly, the band at $1152 \mathrm{~cm}^{-1}$ shifted toward a relatively low wavenumber as the potential became increasingly negative. This behavior, known as the Stark tuning effect, demonstrated that the phosphate was adsorbed on the catalyst surface [47]. Contrarily, there were no phosphate bands in the $0.1 \mathrm{M} \mathrm{NaOH} / 0.9 \mathrm{M} \mathrm{NaClO}_{4}$ electrolyte. The strongest Raman signals were produced by $\mathrm{CuO}_{x} /$ $(\mathrm{OH})_{\mathrm{y}}$ at $\sim 530 \mathrm{~cm}^{-1}$ and $\mathrm{ClO}_{4}{ }^{-}$in the bulk electrolyte at $935 \mathrm{~cm}^{-1}$. Based on these results, they proposed that the competitive adsorption of $\mathrm{CO}$ and phosphate affects the coverage and heterogeneity of the adsorbed $\mathrm{CO}$, resulting in different CORR activities [47]. This study shows that the adsorption behavior of electrolyte species and their interactions with reaction intermediates can be observed by SHINERS.

\section{Carbon monoxide oxidation reaction}

$\mathrm{CO}$ has been reported to poison Pt catalyst surfaces during oxidation reactions in the anode of a fuel cell because it possesses a strong binding affinity with Pt surfaces, 


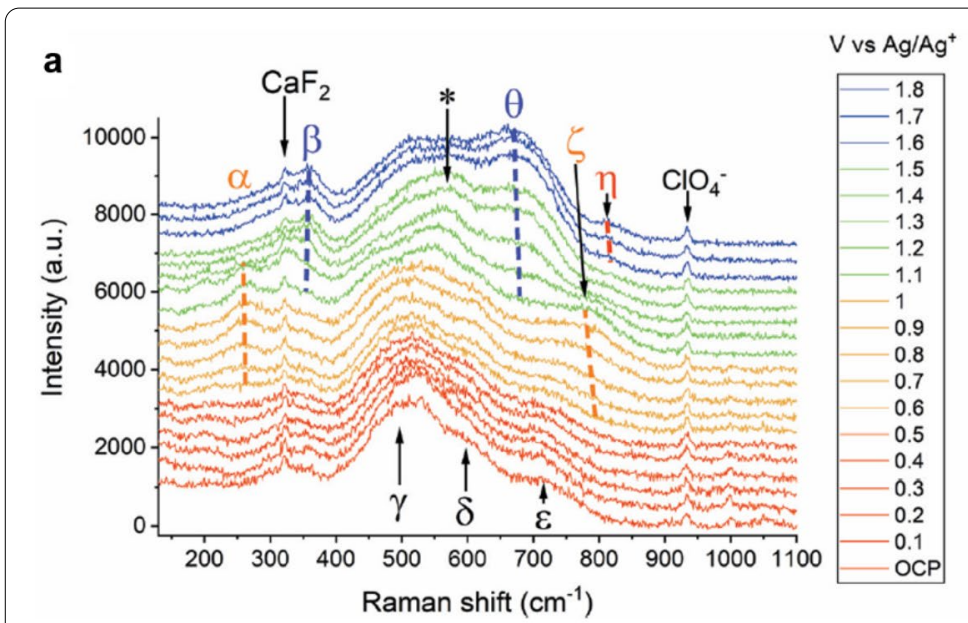

b

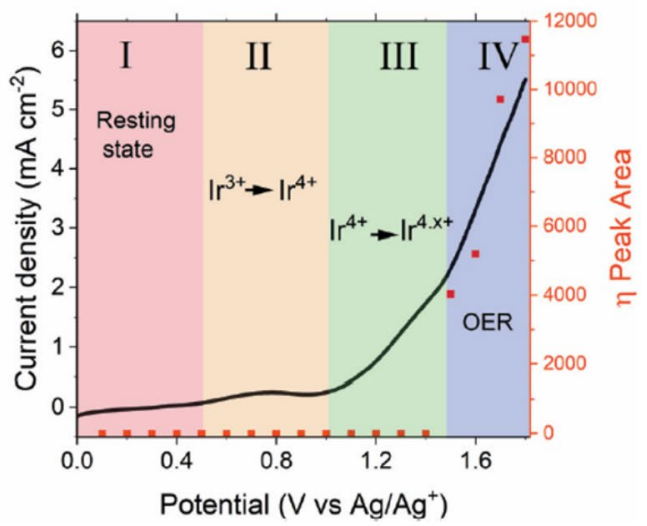

Fig. 9 a In situ Raman spectra of an $\mathrm{Au@SiO}_{2}$ particle-coated IrO film measured in a $1 \mathrm{M} \mathrm{NaClO}_{4}(\mathrm{pH} 10)$ electrolyte at various potentials. b OER current density and $\eta$ peak area as a function of the potential. The voltammogram was measured at a scan rate of $5 \mathrm{mV} \mathrm{s}^{-1}$ in $1 \mathrm{M} \mathrm{NaClO}_{4}\left(\mathrm{pH}_{10}\right.$ ) adjusted with $\mathrm{NaOH}$, reproduced with permission from [46]. Copyright (2020) The Royal Society of Chemistry

which can decrease the catalyst durability and performance [70]. Understanding the adsorption and oxidation of $\mathrm{CO}$ molecules is an important step in designing enhanced catalysts. According to previous studies [65], the Co electrooxidation reaction occurs through a surface bimolecular reaction in which the $\mathrm{CO}^{*}$ and $\mathrm{OH}^{*}$ intermediates adsorbed on the catalyst surface participate in the formation of $\mathrm{COOH}^{*}$ intermediates, as shown in Fig. 8a. Thereafter, the $\mathrm{COOH}^{*}$ intermediate is further oxidized into carbon dioxide and released into the solution.

The Tian group used SHINERS to understand the electrooxidation mechanism of $\mathrm{CO}$ on $\mathrm{Pt}(\mathrm{hkl})$ surfaces in acidic conditions $[64,71]$. As shown in Fig. $8 \mathrm{~b}$ and c, they developed a satellite structure using nanocatalysts deposited on $\mathrm{Au} @ \mathrm{SiO}_{2}$ nanoparticles. Probing nanocatalysts closely attached to the $\mathrm{SiO}_{2}$ shell can amplify the Raman signals from chemical species adsorbed on the catalyst surface. In situ Raman spectra were recorded in a $0.1 \mathrm{M}$ $\mathrm{HClO} 4$ aqueous electrolyte over a potential range of 0.1$1.1 \mathrm{~V}[64,71]$

Figure $8 \mathrm{~d}-\mathrm{e}$ shows the peaks recorded at the initial potential $(0.1 \mathrm{~V})$, including the $\mathrm{Pt}-\mathrm{C}$ stretching mode of $\mathrm{CO}$ absorbed on the bridge site $\left(410 \mathrm{~cm}^{-1}\right)$ and top site $\left(480 \mathrm{~cm}^{-1}\right)$, the symmetric stretching mode of the $\mathrm{ClO}_{4}{ }^{-}$ion $\left(933 \mathrm{~cm}^{-1}\right)$, and the $\mathrm{C}-\mathrm{O}$ stretching mode of $\mathrm{CO}$ absorbed on the bridge site $\left(1780 \mathrm{~cm}^{-1}\right)$ and top site $\left(2050 \mathrm{~cm}^{-1}\right)$. However, on $\mathrm{Pt}(100)$ surface at 0.2 and $0.3 \mathrm{~V}$, two other Raman peaks appeared at $1090 \mathrm{~cm}^{-1}$ and $1005 \mathrm{~cm}^{-1}$, respectively. To confirm the assignment of the peaks, isotopic substitution with deuterium was conducted, and it was discovered that both peaks shifted to lower wavenumber. These results indicated the intermediate species responsible for the vibration contains a hydrogen atom. Furthermore, the DFT calculations revealed that the peak at $1005 \mathrm{~cm}^{-1}$ is assigned to the $\mathrm{C}-\mathrm{OH}$ stretching vibration of the $\mathrm{COOH}^{*}$ intermediate, while the peak at $1090 \mathrm{~cm}^{-1}$ is attributed to the bending mode of $\mathrm{OH}^{*}$ absorbed on the Pt surface [65]. These SHINERS results provided improved insight into the $\mathrm{CO}$ adsorption and oxidation processes that occur during the anode reaction.

\section{Water oxidation reaction}

The water-splitting reaction has been investigated as a promising solution for the generation of hydrogen energy from renewable sources. $\mathrm{IrO}_{\mathrm{x}}$ is known as a water oxidation catalyst that has good stability under acidic conditions and the lowest overpotentials for OERs [46]. Although $\operatorname{IrO}_{x}$ has been studied for a long time, the OER mechanism for $\operatorname{IrO}_{x}$ remains still unknown.

Cowen's group used SHINERS to investigate the water oxidation intermediates on $\mathrm{IrOx}$ electrodes in a $1 \mathrm{M} \mathrm{NaClO}_{4}$ electrolyte at $\mathrm{pH} 10$ [46]. The potential was scanned from the OCP to $1.8 \mathrm{~V}$ vs. $\mathrm{Ag} / \mathrm{Ag}^{+}$potential sweep while recording the in situ Raman spectra (Fig. 9a). The result revealed that an iridium oxo intermediate $(\mathrm{Ir}=\mathrm{O})$ indicated by $\eta$ was formed above $1.6 \mathrm{~V}$. Furthermore, the Raman peak of the $\mathrm{Ir}=\mathrm{O}$ species was discovered to have a relationship with the OER current density, as shown in Fig. 9b. The SHINERS result helped to experimentally support the OER mechanism of the proposed IrOx catalysts (see Table 2). 
Table 2 Raman peak assignment of $\mathrm{IrO}_{\mathrm{x}}$ films captured using the SHINERS technique (Fig. 9a) [46]

\begin{tabular}{|c|c|c|c|}
\hline Label & Peak position $\left[\mathrm{cm}^{-1}\right]$ & Assignment & Species \\
\hline a & 262 & Ir-O-Ir twist & $\mid r^{4+}$ \\
\hline$\beta$ & 357 & Ir-O-Ir twist & $\mid r^{4 . x+}$ \\
\hline Y & 504 & Ir-O-Ir stretch & $\mid r^{4+}$ \\
\hline$\delta$ & 608 & Ir-O-Ir stretch & $\mid r^{3+}$ \\
\hline$\varepsilon$ & 719 & Ir-O-Ir stretch & $\mid r^{4+}$ \\
\hline$\zeta$ & 773 & Ir-O-Ir stretch & $\mid r^{4+}$ \\
\hline$\theta$ & 672 & Ir-O-Ir stretch & $\mid r^{4 \cdot x+}$ \\
\hline \multirow[t]{2}{*}{$\eta$} & 813 in $\mathrm{H} 2 \mathrm{O}$ & $\mathrm{Ir}=\mathrm{O}$ stretch & $\mid r^{4 . x+}$ \\
\hline & 817 in D2O & & \\
\hline
\end{tabular}

\section{Nitrate reduction reaction}

Ammonia $\left(\mathrm{NH}_{3}\right)$ is an essential chemical feedstock because of its wide applications, such as pharmaceuticals and fertilizers. It is also considered a hydrogen energy carrier for a carbon-neutral future. The HaberBosch process, which requires high temperatures and pressures, is mainly used to manufacture $\mathrm{NH}_{3}$ industrially. Industrial $\mathrm{NH}_{3}$ production causes a $1.44 \%$ increase in global $\mathrm{CO}_{2}$ emissions because of its harsh synthesis conditions [72]. Currently, the removal of nitrate from industrial wastewater and its electrochemical conversion into $\mathrm{NH}_{3}$ has been an important topic in the environmental research field. The $\mathrm{Cu}$ metal is one of the most active nitrate electrocatalysts; however, there is still a lack of understanding regarding the surface chemical species and their influence on the reduction activity on $\mathrm{Cu}$ surfaces [50].

The Gewirth group used SHINERS to investigate the active sites and reaction intermediates on nitrate reduction into $\mathrm{NH}_{3}$ for all $\mathrm{Cu}(\mathrm{hkl})$ surface with and without $\mathrm{HCl}$ addition (Fig. 10) [50]. They mentioned that the RDS is the initial two-electron reduction of nitrate into nitrite.
The nitrous oxide species (mentioned with D, E, and G to $O$ peaks in Fig. 10) have similar spectra on the $\mathrm{Cu}(100)$ (Fig. 10a) and $\mathrm{Cu}(11)$ surfaces (Fig. 10b), whereas $\mathrm{Cu}_{2} \mathrm{O}$ species (described with A and B letters) only occurred on the $\mathrm{Cu}(110)$ surface. Such a different active site was proposed to affect the rate-determining step for $\mathrm{NH}_{3}$ production, which is the two-electron reduction of $\mathrm{NO}_{3}{ }^{-}$to $\mathrm{NO}_{2}{ }^{-}$. As shown in the linear sweep voltammetry (LSV) curves, the $\mathrm{Cu}(110)$ surface showed a more positive onset potential for nitrate reduction than the $\mathrm{Cu}(100)$ surface (Fig. 10c). Based on these results, SHINERS was able to confirm the role of the oxidized $\mathrm{Cu}$ surface in nitrate reduction (see Table 3).

\section{Conclusion}

In summary, we review the fundamental principles and historical development of SHINERS, as well as discuss new insights into investigating reaction intermediates, catalytic active sites, and related reaction mechanisms using the SHINERS method. SHINERS is a critical strategy for capturing intermediate species of various electrochemical reactions even on smooth electrodes and metal oxide films despite low SERS activity, as demonstrated in the mechanistic studies for ORRs and COORs on different Pt single crystal surfaces. Simultaneously, SHINs can significantly amplify SERS signals from a thin layer of surface reactive sites. As shown in the case studies of water oxidation reactions, CORRs, and $\mathrm{NO}_{3}$ RRs, SHINERS allows for monitoring of the potential-dependent behaviors of electrode surfaces and for determining the catalytically active sites by comparing the SHINERS results with chronoamperometric and linear sweep voltammetric measurements. Therefore, SHINERS can be used to investigate a reaction mechanism regardless of the type of electrode, and it has a wide potential in a variety of electrocatalysis and electrochemical systems. We believe that this review not only provides a comprehensive understanding of the SHINERS technique
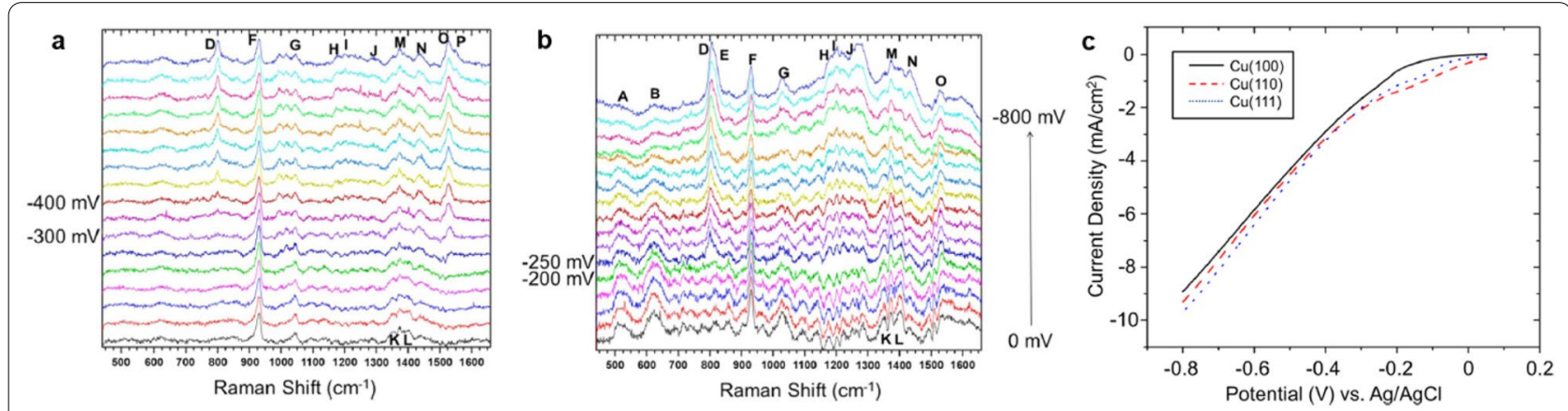

Fig. 10 In situ Raman spectra of $\mathbf{a} \mathrm{Cu}(100)$ and $\mathbf{b} \mathrm{Cu}(110)$ electrodes measure in a $0.1 \mathrm{M} \mathrm{HClO}_{4} / 0.05 \mathrm{M} \mathrm{HNO}_{3}$ solution during cathodic polarization from 0 to $800 \mathrm{mV}$ vs. Ag/AgCl. c Linear sweep voltammetry of $\mathrm{Cu}(100), \mathrm{Cu}(110)$, and $\mathrm{Cu}(111)$ electrodes in a $0.1 \mathrm{M} \mathrm{HClO}_{4} / 0.05 \mathrm{M} \mathrm{HNO}_{3}$ solution during cathodic polarization from 0 to $800 \mathrm{mV}$ vs. Ag/AgCl, reproduced with permission from [50]. Copyright (2016) Elsevier 
Table 3 Raman peak assignment for the $\mathrm{NO}_{3} \mathrm{RR}$ on the $\mathrm{Cu}(100)$ and Cu(110) surfaces observed using the SHINERS technique [50]

\begin{tabular}{|c|c|c|c|}
\hline \multirow[t]{2}{*}{ Peak } & \multicolumn{2}{|c|}{ Raman shift $\left[\mathrm{cm}^{-1}\right]$} & \multirow[t]{2}{*}{ Assignment } \\
\hline & $\mathrm{Cu}(100)$ & $\mathrm{Cu}(110)$ & \\
\hline A & & 509 & $\mathrm{Cu}_{2} \mathrm{O}$ \\
\hline B & & 619 & $\mathrm{Cu}_{2} \mathrm{O}$ \\
\hline D & 801 & 801 & $\mathrm{NO}_{2}^{-}$bending \\
\hline $\mathrm{E}$ & & 817 & $\mathrm{NO}_{2}^{-}$bending \\
\hline $\mathrm{F}$ & 931 & 931 & $\mathrm{v}(\mathrm{Cl}-\mathrm{O})$ \\
\hline G & 1044 & 1027 & $\mathrm{~V}_{\mathrm{s}} \mathrm{NO}$ stretching \\
\hline H & 1180 & 1183 & $\mathrm{v}_{\mathrm{s}} \mathrm{NO}_{2}^{-}$, chelating nitrito \\
\hline । & 1200 & 1208 & $\mathrm{v}(\mathrm{N}-\mathrm{O})$ nitrito orientation \\
\hline J & 1281 & 1272 & $\mathrm{v}_{\mathrm{a}} \mathrm{NO}_{2}^{-}$, chelating nitrito \\
\hline K & 1350 & 1349 & $\mathrm{~V}_{\mathrm{s}} \mathrm{NO}_{2}^{-}$of $\mathrm{NO}_{3}^{-}$ \\
\hline L & 1372 & 1373 & $\mathrm{va}_{\mathrm{a}} \mathrm{NO}_{2}^{-}$of $\mathrm{NO}_{3}^{-}$ \\
\hline M & 1372 & 1374 & $\mathrm{v}(\mathrm{N}=\mathrm{O})$, nitrito orientation \\
\hline N & 1434 & 1431 & $v(N=O)$, bridging nitro \\
\hline O & 1528 & 1531 & $v(N=O)$, nitroxyl \\
\hline $\mathrm{P}$ & & & HNO bending and stretching, nitroxyl \\
\hline
\end{tabular}

in unraveling reaction mechanisms for electrocatalysis but also provides new insights into observing catalyst-electrolyte interfaces that have not been probed.

\section{Acknowledgements}

Not applicable.

\section{Authors' contributions}

$\mathrm{AH}$ and $\mathrm{CWL}$ wrote the manuscript. Both authors read and approved the final manuscript.

\section{Funding}

This work was supported by the National Research Foundation of Korea(NRF) Grant funded by the Korean Government(MSIT)(NRF-2020R1C1C1010963). This work was also supported by Korea Institute of Planning and Evaluation for Technology in Food, Agriculture and Forestry(IPET) and Korea Smart Farm R\&D Foundation(KosFarm) through Smart Farm Innovation Technology Development Program, funded by Ministry of Agriculture, Food and Rural Affairs(MAFRA) and Ministry of Science and ICT(MSIT), Rural Development Administration(RDA)(421036-03-1-HD030). This work was also supported by National R\&D Program through the National Research Foundation of Korea(NRF) funded by Ministry of Science and ICT(2021M3D1A2051636).

\section{Availability of data and materials}

All data presented in this review article are included in the published article which can be found in the references list.

\section{Declarations}

\section{Competing interests}

The authors declare that they have no competing interests.

Received: 22 November 2021 Accepted: 28 January 2022 Published online: 14 February 2022

\section{References}

1. A. Burnham, J. Han, C.E. Clark, M. Wang, J.B. Dunn, I. Palou-Rivera, Environ. Sci. Technol. 46, 619 (2012)

2. C. Kennedy, J. Steinberger, B. Gasson, Y. Hansen, T. Hillman, M. Havránek, D. Pataki, A. Phdungsilp, A. Ramaswami, G.V. Mendez, Environ. Sci. Technol. 43, 7297 (2009)

3. T.R. Anderson, E. Hawkins, P.D. Jones, Endeavour 40(3), 178-187 (2016)

4. bp Statistical Review of World Energy (2020). https://www.bp.com/conte nt/dam/bp/business-sites/en/global/corporate/pdfs/energy-economics/ statistical-review/bp-stats-review-2020-full-report.pdf

5. Y.J. Sa, C.W. Lee, S.Y. Lee, J. Na, U. Lee, Y.J. Hwang, Chem. Soc. Rev. 49, 6632 (2020)

6. T.A.S.A. Abbasi, Renew. Sustain. Energy Rev. 15, 3034 (2011)

7. Z.W. She, J. Kibsgaard, C.F. Dickens, I. Chorkendorff, J.K. Nørskov, T.F. Jaramillo, Science 355, 146 (2017)

8. E.J. Askins, M.R. Zoric, M. Li, Z. Luo, K. Amine, K.D. Glusac, Nat. Commun. 12, 1 (2021)

9. C.W. Lee, N.H. Cho, S.W. Im, M.S. Jee, Y.J. Hwang, B.K. Min, K.T. Nam, J. Mater. Chem. A 6, 14043 (2018)

10. C.W. Lee, C. Kim, B.K. Min, Nano Converg 6, 8 (2019)

11. J. Chen, G. Liu, Y.Z. Zhu, M. Su, P. Yin, X.J. Wu, Q. Lu, C. Tan, M. Zhao, Z. Liu, W. Yang, H. Li, G.H. Nam, L. Zhang, Z. Chen, X. Huang, P.M. Radjenovic, W. Huang, Z.Q. Tian, J.F. Li, H. Zhang, J. Am. Chem. Soc. 142, 7161 (2020)

12. K. Zhu, X. Zhu, W. Yang, Angew. Chem. Int. Ed. 58, 1252 (2019)

13. W. Jiao, C. Chen, W. You, G. Chen, S. Xue, J. Zhang, J. Liu, Y. Feng, P. Wang, Y. Wang, H. Wen, R. Che, Appl. Catal. B Environ. 262, 118298 (2020)

14. Y. Deng, B.S. Yeo, ACS Catal. 7, 7873 (2017)

15. Y. Zhao, X. Chang, A.S. Malkani, X. Yang, L. Thompson, F. Jiao, B. Xu, J. Am. Chem. Soc. 142, 9735-9743 (2020)

16. M. Moradzaman, G. Mul, ChemElectroChem 8, 1478 (2021)

17. C. Long, J. Han, J. Guo, C. Yang, S. Liu, Z. Tang, Chem Catal. 1, 509 (2021)

18. I.V. Chernyshova, P. Somasundaran, S. Ponnurangam, Proc. Natl. Acad. Sci. USA 115, E9261 (2018)

19. J.F. Li, Y.J. Zhang, S.Y. Ding, R. Panneerselvam, Z.Q. Tian, Chem. Rev. 117, 5002 (2017)

20. J.C. Dong, X.G. Zhang, V. Briega-Martos, X. Jin, J. Yang, S. Chen, Z.L. Yang, D.Y. Wu, J.M. Feliu, C.T. Williams, Z.Q. Tian, J.F. Li, Nat. Energy 4, 60 (2019)

21. J.F. Li, Y.F. Huang, Y. Ding, Z.L. Yang, S.B. Li, X.S. Zhou, F.R. Fan, W. Zhang, Z.Y. Zhou, D.Y. Wu, B. Ren, Z.L. Wang, Z.Q. Tian, Nature 464, 392 (2010)

22. S.Y. Ding, J. Yi, J.F. Li, B. Ren, D.Y. Wu, R. Panneerselvam, Z.Q. Tian, Nat. Rev. Mater. 1, 6 (2016)

23. S. Lal, S. Link, N.J. Halas, Nat. Photon. 1, 641 (2007)

24. S. Cong, X. Liu, Y. Jiang, W. Zhang, and Z. Zhao, The Innovation 1, 3, 100051 (2020).

25. J. Zuloaga, E. Prodan, P. Nordlander, Nano Lett. 9, 887 (2009)

26. A. Tittl, X. Yin, H. Giessen, X.D. Tian, Z.Q. Tian, C. Kremers, D.N. Chigrin, N. Liu, Nano Lett. 13, 1816 (2013)

27. H. Zhang, S. Duan, P.M. Radjenovic, Z.Q. Tian, J.F. Li, Acc. Chem. Res. 53 729 (2020)

28. M. Fleischmann, P.J. Hendra, A.J. McQuillan, Chem. Phys. Lett. 26, 163 (1974)

29. D.L. Jeanmaire, R.P. Van Duyne, J. Electroanal Chem. 84, 1 (1977)

30. M. Moskovits, J. Chem. Phys. 69, 4159 (1978)

31. K. Kuruvinashetti, Y. Zhang, J. Li, N. Kornienko, New J. Chem. 44, 19953 (2020)

32. A.R. Shafiqa, A. Abdul Aziz, B. Mehrdel, J. Phys. Conf. Ser. 1083, 12040 (2020)

33. P.-P. Fang, J. Li, Z.-L. Yang, L.-M. Li, B. Ren, Z. Tian, J. Raman Spectrosc. 39, 1679 (2008)

34. S. Cortijo-Campos, R. Ramírez-Jiménez, E. Climent-Pascual, M. AguilarPujol, F. Jiménez-Villacorta, L. Martínez, R. Jiménez-Riobóo, C. Prieto, A. de Andrés, Mater. Des. 192, 108702 (2020)

35. M. Hlaing, B. Gebear-Eigzabher, A. Roa, A. Marcano, D. Radu, C.Y. Lai, Opt. Mater. (Amst). 58, 439 (2016)

36. F. Benz, R. Chikkaraddy, A. Salmon, H. Ohadi, B. De Nijs, J. Mertens, C. Carnegie, R.W. Bowman, J.J. Baumberg, J. Phys. Chem. Lett. 7, 2264 (2016)

37. S.B. Li, L.M. Li, J.R. Anema, J.F. Li, Z.L. Yang, B. Ren, J.J. Sun, Z.Q. Tian, Zeitschrift. Fur. Phys. Chem. 225, 775 (2011)

38. K. Kołątaj, J. Krajczewski, A. Kudelski, Appl. Surf. Sci. 456, 932 (2018)

39. J. Krajczewski, A. Michałowska, A. Kudelski, Spectrochim. Acta Part A 225 117469 (2020) 
40. J. Turkevich, P.C. Stevenson, J. Hillier, Discuss. Faraday Soc. 11, 55 (1951)

41. G. Frens, Nat. Phys. Sci. 241, 20 (1973)

42. T.K. Sau, C.J. Murphy, J. Am. Chem. Soc. 126, 8648 (2004)

43. T.T.B. Quyen, C.C. Chang, W.N. Su, Y.H. Uen, C.J. Pan, J.Y. Liu, J. Rick, K.Y. Lin, B.J. Hwang, J. Mater. Chem. B 2, 629 (2014)

44. J.F. Li, J.R. Anema, Y.C. Yu, Z.L. Yang, Y.F. Huang, X.S. Zhou, B. Ren, Z.Q. Tian, Chem. Commun. 47, 2023 (2011)

45. J.F. Li, S.B. Li, J.R. Anema, Z.L. Yang, Y.F. Huang, Y. Ding, Y.F. Wu, X.S. Zhou, D.Y. Wu, B. Ren, Z.L. Wang, Z.Q. Tian, Appl. Spectrosc. 65, 620 (2011)

46. K.H. Saeed, M. Forster, J.F. Li, L.J. Hardwick, A.J. Cowan, Chem. Commun. 56, $1129(2020)$

47. J. Li, X. Chang, H. Zhang, A.S. Malkani, M. Jeng Cheng, B. Xu, Q. Lu, Nat. Commun. 12, 3264 (2021)

48. T.A. Galloway, L.J. Hardwick, J. Phys. Chem. Lett. 7, 2119 (2016)

49. Y.F. Huang, P.J. Kooyman, M.T.M. Koper, Nat Commun 7, 12440 (2016)

50. D.P. Butcher, A.A. Gewirth, Nano Energy 29, 457 (2016)

51. B.L. Sanchez-Gaytan, P. Swanglap, T.J. Lamkin, R.J. Hickey, Z. Fakhraai, S. Link, S.J. Park, J. Phys. Chem. C 116, 10318 (2012)

52. K.L. Kelly, E. Coronado, L.L. Zhao, G.C. Schatz, J. Phys. Chem. B 107, 668 (2003)

53. M. Rycenga, M.R. Langille, M.L. Personick, T. Ozel, C.A. Mirkin, Nano Lett. 12,6218 (2012)

54. Q. Zhang, N. Large, H. Wang, A.C.S. Appl, Mater. Interfaces 6, 17255 (2014)

55. J.H. Lee, K.J. Gibson, G. Chen, Y. Weizmann, Nat Commun 6, 7571 (2015)

56. R. Keunen, D. MacOretta, N. Cathcart, V. Kitaev, Nanoscale 8, 2575 (2016)

57. V. Uzayisenga, X.D. Lin, L.M. Li, J.R. Anema, Z.L. Yang, Y.F. Huang, H.X. Lin, S.B. Li, J.F. Li, Z.Q. Tian, Langmuir 28, 9140 (2012)

58. B. Wiley, Y. Sun, Y. Xia, Acc. Chem. Res. 40, 1067 (2007)

59. P. Botella, I. Ortega, M. Quesada, R.F. Madrigal, C. Muniesa, A. Fimia, E. Fernández, A. Corma, Dalt. Trans. 41, 9286 (2012)

60. L.M. Liz-marza, M. Giersig, P. Mulvaney, Langmuir 12(18), 4329 (1996)

61. J.F. Li, X.D. Tian, S.B. Li, J.R. Anema, Z.L. Yang, Y. Ding, Y.F. Wu, Y.M. Zeng, Q.Z. Chen, B. Ren, Z.L. Wang, Z.Q. Tian, Nat. Protoc. 8, 52 (2013)

62. W. Zhang, J.C. Dong, C.Y. Li, S. Chen, C. Zhan, R. Panneerselvam, Z.L. Yang, J.F. Li, Y.L. Zhou, J. Raman Spectrosc. 46, 1200 (2015)

63. A. Acharya, S. Dubbu, S. Kumar, N. Kumari, Y. Kim, S. So, T. Kwon, Z. Wang J. Park, Y.K. Cho, J. Rho, S.H. Oh, A. Kumar, I.S. Lee, J. Am. Chem. Soc. 143, $10582(2021)$

64. M.M. Liang, Y.H. Wang, R. Shao, W.M. Yang, H. Zhang, H. Zhang, Z.L. Yang, J.F. Li, Z.Q. Tian, Electrochem. Commun. 81, 38 (2017)

65. M. Su, J.C. Dong, J.B. Le, Y. Zhao, W.M. Yang, Z.L. Yang, G. Attard, G.K. Liu, J. Cheng, Y.M. Wei, Z.Q. Tian, J.F. Li, Angew. Chem. Int. Ed. 59, 23554 (2020)

66. C.W. Lee, K.D. Yang, D.H. Nam, J.H. Jang, N.H. Cho, S.W. Im, K.T. Nam, Adv. Mater. 30, 1704717 (2018)

67. J. Greeley, I.E.L. Stephens, A.S. Bondarenko, T.P. Johansson, H.A. Hansen, T.F. Jaramillo, J. Rossmeisl, I. Chorkendorff, J.K. Nørskov, Nat. Chem. 1, 552 (2009)

68. Y. Wang, J. Le, W. Li, J. Wei, P.M. Radjenovic, H. Zhang, X. Zhou, J. Cheng, Z. Tian, J. Li, Angew. Chem. 131, 16208 (2019)

69. J.C. Dong, M. Su, V. Briega-Martos, L. Li, J.B. Le, P. Radjenovic, X.S. Zhou, J.M. Feliu, Z.Q. Tian, J.F. Li, J. Am. Chem. Soc. 142, 715 (2020)

70. C.W. Lee, S.J. Shin, H. Jung, D.L.T. Nguyen, S.Y. Lee, W.H. Lee, D.H. Won, M.G. Kim, H.S. Oh, T. Jang, H. Kim, B.K. Min, Y.J. Hwang, ACS Energy Lett. 4, 2241 (2019)

71. H. Zhang, C. Wang, H.L. Sun, G. Fu, S. Chen, Y.J. Zhang, B.H. Chen, J.R. Anema, Z.L. Yang, J.F. Li, Z.Q. Tian, Nat. Commun. 8, 1 (2017)

72. Z.Y. Wu, M. Karamad, X. Yong, Q. Huang, D.A. Cullen, P. Zhu, C. Xia, Q. Xiao, M. Shakouri, F.Y. Chen, J.Y. Timothy Kim, Y. Xia, K. Heck, Y. Hu, M.S. Wong, Q. Li, I. Gates, S. Siahrostami, H. Wang, Nat. Commun. 12, 2870 (2021)

\section{Publisher's Note}

Springer Nature remains neutral with regard to jurisdictional claims in published maps and institutional affiliations. 